\title{
M1 Receptors Mediate Cholinergic Modulation of Excitability in Neocortical Pyramidal Neurons
}

\author{
Allan T. Gulledge, ${ }^{1}$ David J. Bucci, ${ }^{2}$ Sunny S. Zhang, ${ }^{2}$ Minoru Matsui, ${ }^{1,3}$ and Hermes H. Yeh ${ }^{1}$ \\ ${ }^{1}$ Department of Physiology, Dartmouth Medical School, Lebanon, New Hampshire 03756-0001, 2Department of Psychological and Brain Sciences, \\ Dartmouth College, Hanover, New Hampshire 03755, and '3Department of Pharmacy, Chiba Institute of Science, Choshi, Chiba \\ 288-0025, Japan
}

ACh release into the rodent prefrontal cortex is predictive of successful performance of cue detection tasks, yet the cellular mechanisms underlying cholinergic modulation of cortical function are not fully understood. Prolonged ("tonic") muscarinic ACh receptor (mAChR) activation increases the excitability of cortical pyramidal neurons, whereas transient ("phasic") mAChR activation generates inhibitory and/or excitatory responses, depending on neuron subtype. These cholinergic effects result from activation of "M1-like" $\mathrm{mAChRs} \mathrm{(M1,}$ M3, and M5 receptors), but the specific receptor subtypes involved are not known. We recorded from cortical pyramidal neurons from wild-type mice and mice lacking M1, M3, and/or M5 receptors to determine the relative contribution of M1-like mAChRs to cholinergic signaling in the mouse prefrontal cortex. Wild-type neurons in layer 5 were excited by tonic mAChR stimulation, and had biphasic inhibitory followed by excitatory, responses to phasic ACh application. Pyramidal neurons in layer $2 / 3$ were substantially less responsive to tonic and phasic cholinergic input. Cholinergic effects were largely absent in neurons from mice lacking M1 receptors, but most were robust in neurons lacking M3, M5, or both M3 and M5 receptors. The exception was tonic cholinergic suppression of the afterhyperpolarization in layer 5 neurons, which was absent in cells lacking either M1 or M3 receptors. Finally, we confirm a role for M1 receptors in behavior by demonstrating cue detection deficits in M1-lacking mice. Together, our results demonstrate that M1 receptors facilitate cue detection behaviors and are both necessary and sufficient for most direct effects of ACh on pyramidal neuron excitability.

\section{Introduction}

Cortical pyramidal neurons are prominent targets of cholinergic input, and recent studies have described multiple, even opposing, actions of ACh on pyramidal neuron excitability. Prolonged ("tonic") exposure to cholinergic agonists generally excites pyramidal neurons by depolarizing the resting membrane potential (RMP), suppressing the afterhyperpolarization (AHP) that follows bursts of action potentials, and revealing an afterdepolarization (ADP) that can be sufficiently powerful to initiate sustained action potential generation (Schwindt et al., 1988; Klink and Alonso, 1997; Haj-Dahmane and Andrade, 1998; Egorov et al., 2002). However, transient ("phasic") exposure to ACh generates biphasic responses in layer 5 pyramidal neurons in which excitation is preceded by hyperpolarization that strongly inhibits action potential generation (Gulledge and Stuart, 2005). Recent data indicate that phasic and tonic ACh release can occur concurrently in the cortex of awake animals during cue detection tasks (Parikh et al., 2007), and individual cortical pyramidal neurons can faithfully respond to these co-occurring signals in vitro (Gulledge and Stuart, 2005).

Received March 22, 2009; revised June 19, 2009; accepted June 26, 2009.

This work was supported by Public Health Service Grants R01 MH83806 (to A.T.G.), R01 NS048603 (to H.H.Y.), and R01 AA014689 (to H.H.Y.) and the Neuroscience (enter at Dartmouth (to A.T.G. and D.J.B.). We thank Meijie Li, Daniel Avesar, Genevieve St. Germain, and Walburga Croteau for technical assistance.

Correspondence should be addressed to Dr. Allan T. Gulledge, Department of Physiology, Dartmouth Medical School, One Medical Center Drive, Lebanon, NH 03756-0001. E-mail: allan.gulledge@dartmouth.edu.

D0I:10.1523/JNEUROSCI.1366-09.2009

Copyright $\odot 2009$ Society for Neuroscience $\quad$ 0270-6474/09/299888-15\$15.00/0
In mature pyramidal neurons, postsynaptic effects of ACh on neuronal excitability are mediated by muscarinic ACh receptors (mAChRs) (Gulledge and Stuart, 2005), of which there are five subtypes (M1-M5) expressed in the neocortex (Flynn et al., 1995). The mAChR subtypes have been classified into two families based on differential coupling to intracellular signaling cascades. Members of the "M1-like" family of mAChRs (M1, M3, and M5 receptors) are associated with the $G_{q}$ subtype of G-protein $\alpha$ subunit and phosphatidylinositol turnover. In contrast, members of the "M2-like" family (M2 and M4 receptors) are generally linked via $G_{i} \alpha$ subunits to inhibition of adenylyl cyclase (for review, see Lanzafame et al., 2003). Pharmacological data in cortical neurons indicate that both excitatory and inhibitory effects of ACh require M1-like mAChRs (Gulledge and Stuart, 2005; Gulledge et al., 2007). However, the specific receptor subtype(s) involved, and whether all cholinergic effects depend on the same or different M1-like mAChR subunits, remains unknown. Conclusive identification of the specific mAChR subtype(s) involved in cholinergic modulation of pyramidal neurons remains an important outstanding priority, because these receptors are potential targets for therapeutic intervention in cognitive disorders involving decreased cholinergic innervation of the cortex (Eglen et al., 1999; Clader and Wang, 2005; Ringman and Cummings, 2006; Fisher, 2008).

The availability of "knock-out" mice lacking specific mAChR subunits provides an alternative approach for directly identifying the $\mathrm{mAChR}$ subunits involved in cortical cholinergic signaling. Here, we use mAChR knock-out mice to identify the receptor 
subtypes responsible for excitatory and inhibitory signaling in neocortical pyramidal neurons. Our results demonstrate that activation of a single M1-like $\mathrm{mAChR}$, the $\mathrm{M} 1$ receptor, is required for the postsynaptic effects of ACh on pyramidal neuron excitability. Furthermore, our data reveal an unexpected specialized role for M3 receptors in gating M1 receptor-associated cholinergic suppression of the AHP. Finally, we confirm a role for M1 receptors in behavior by finding deficits in cue detection behaviors in M1-lacking mice.

\section{Materials and Methods}

Animals. Experiments were performed on 6- to-8-week-old wild-type or genetically modified C57BL/6 mice, according to methods approved by the Institutional Animal Care and Use Committee of Dartmouth College. The generation and characterization of knock-out mice for M1, M3, and M5 receptors has been described previously (Matsui et al., 2000; Ohno-Shosaku et al., 2003; Nakamura et al., 2004). All mice used in this study were backcrossed to C57BL/6JJcl (CLEA Japan) for at least 10 generations.

Electrophysiology. Recordings were made from visually identified pyramidal neurons in coronal brain slices (250 or $180 \mu \mathrm{m}$ thick) of the medial prefrontal cortex (mPFC). Ice-cold cutting solutions contained the following (in mM): $125 \mathrm{NaCl}, 25 \mathrm{NaHCO}_{3}, 3 \mathrm{KCl}, 1.25 \mathrm{NaH}_{2} \mathrm{PO}_{4}, 0.5$ $\mathrm{CaCl}_{2}, 6 \mathrm{MgCl}_{2}$, and 25 glucose (bubbled with $95 \% \mathrm{O}_{2} / 5 \% \mathrm{CO}_{2}$ ). Slices were stored and perfused with a similar artificial CSF (aCSF) containing $2 \mathrm{mM} \mathrm{CaCl}_{2}$ and $1 \mathrm{mM} \mathrm{MgCl}_{2}$ and continuously bubbled with $95 \% \mathrm{O}_{2} / 5 \%$ $\mathrm{CO}_{2}$. Whole-cell recording pipettes (5-8 $\mathrm{M} \Omega$ ) contained the following (in $\mathrm{mm}$ ): 140 potassium gluconate, $2 \mathrm{NaCl}, 2 \mathrm{MgCl}_{2}, 10$ HEPES, 3 $\mathrm{Na}_{2} \mathrm{ATP}$, and $0.3 \mathrm{NaGTP}$ (pH 7.2 with $\mathrm{KOH}$ ). In some experiments, biocytin $(7 \mathrm{mg} / \mathrm{ml})$ was included in the pipette solution to allow for subsequent visualization of neurons in fixed tissue (see below). Data were acquired using a BVC-700 amplifier (Dagan) and an ITC-18 digitizer (HEKA Instruments) attached to a computer running AxoGraphX data acquisition software (AxographX). Data were filtered at $5 \mathrm{kHz}$ and digitized at 25 or $40 \mathrm{kHz}$. Whole-cell series resistance was generally between 10 and $25 \mathrm{M} \Omega$ and was maximally compensated. Membrane potentials were corrected for the liquid junction potential $(12 \mathrm{mV})$. All experiments were carried out at $35 \pm 1{ }^{\circ} \mathrm{C}$.

Phasic cholinergic responses were generated by focal application of ACh $(100 \mu \mathrm{M})$ dissolved in aCSF and loaded into a patch pipette connected to a pneumatic drug-application device (Toohey). AChcontaining patch pipettes were placed $\sim 20 \mu \mathrm{m}$ from the soma of the recorded neuron, and $\mathrm{ACh}$ was applied for $40 \mathrm{~ms}$ at $10 \mathrm{psi}$, unless otherwise noted. When ACh application was delivered at RMPs, cells were first "primed" via $5 \mathrm{~s}$ of current-induced action potential generation to maximize subsequent cholinergic responses, which can otherwise "rundown" during prolonged periods of inactivity (Gulledge et al., 2007). The magnitude of ACh-induced inhibition was measured as the amplitude of hyperpolarizing responses from RMPs. For neurons in which inhibitory cholinergic signaling was absent (such as layer 2/3 neurons, or following pharmacological or genetic manipulations), "responses" to focal ACh application at RMPs were measured $900 \mathrm{~ms}$ following ACh application, a time point corresponding to peak hyperpolarization in neurons that are inhibited by ACh (Gulledge and Stuart, 2005).

To measure phasic cholinergic excitation, ACh was focally applied during periods of action potential generation induced by somatic current injection (between 5 and $10 \mathrm{~Hz}$; mean frequency, $6.2 \pm 2.3 \mathrm{~Hz} ; n=109$ ). Under these conditions, ACh generates a transient suppression of activity $(\sim 1 \mathrm{~s})$ that is followed by renewed action potential generation occurring at higher frequencies than those observed in baseline conditions before ACh application. We calculated the mean instantaneous spike frequency (ISF) during the $8 \mathrm{~s}$ before ACh application, and during six consecutive seconds beginning $2 \mathrm{~s}$ after ACh application (to allow time for inhibitory responses to subside), and quantified cholinergic excitation as the percent change in mean ISF over the two time periods ["spike acceleration" = (mean ISF following ACh application/mean baseline ISF) $\times 100]$.

Tonic cholinergic excitation was assessed by measuring the effect of bath-applied carbachol ( $10 \mu \mathrm{M}$; applied for 5 or $10 \mathrm{~min}$ ) on the RMP, and on two physiological responses that typically follow brief periods of action potential generation: the AHP and the carbachol-induced ADP. Periodic $(0.05 \mathrm{~Hz})$ current injections ( $\sim 450 \mathrm{pA} ; 250 \mathrm{~ms})$, or trains of current injections ( $4 \mathrm{nA} ; 10$ injections of 2 or $3 \mathrm{~ms}$ in duration delivered at $40 \mathrm{~Hz}$ ), were used to evoke brief trains of action potentials. Amplitudes of AHPs and ADPs were measured relative to the membrane potential occurring just before current injections. Peak AHPs were measured as the maximum hyperpolarization occurring within the first $500 \mathrm{~ms}$ following current injections, whereas ADPs were measured as the peak depolarization occurring within the first $1.5 \mathrm{~s}$ following current injections. Measurements of carbachol-induced changes in RMP, AHP, and ADP amplitudes were analyzed only for those neurons that did not develop sustained spontaneous action potential generation during carbachol application.

Histology. Some wild-type neurons were filled with biocytin (see above) for visual confirmation of neuron location and morphology. Slices containing these neurons were fixed overnight in a $0.1 \mathrm{~m}$ PBS containing $4 \%$ paraformaldehyde and $0.2 \%$ picric acid. Slices were then washed several times in PBS and incubated for up to $12 \mathrm{~h}$ in PBS containing $0.25 \%$ Triton X-100 and avidin conjugated to Alexa Fluor 488 (20 $\mu \mathrm{g} / \mathrm{ml}$; Invitrogen). After several washes in PBS, slices were illuminated (488 nm excitation) and visualized using an upright epifluorescence microscope with a $10 \times$ objective lens (Olympus).

Behavior testing. Mice were housed individually and maintained on a 14:10 light-dark cycle throughout the study. The mice were allowed to acclimate to the vivarium for $7 \mathrm{~d}$ with free access to food and water (Purina rodent chow; Nestle Purina) and were then handled by the experimenter for 1-2 min during each of the following $3 \mathrm{~d}$. On the third day, baseline body weight was recorded, and the mice were each fed $3 \mathrm{~g}$ of food. Behavioral training began the next day, and mice were fed after each daily behavioral session to maintain $90 \%$ free-feed body weight.

Training took place in standard conditioning chambers $(21.6 \times$ $17.8 \times 12.7 \mathrm{~cm}$; Med Associates) connected to a computer and enclosed in sound-attenuating shells outfitted with exhaust fans to provide airflow and background noise $(\sim 68 \mathrm{~dB})$. The chambers consisted of three clear acrylic sides and top, an aluminum front wall, and grid floors. A house light provided background illumination of the chamber. A dimly illuminated food cup was recessed in the center of one wall with the bottom of the cup positioned $0.5 \mathrm{~cm}$ above the floor. A $6 \mathrm{~W}$ jeweled panel light served as the visual-conditioned stimulus and was located immediately to the right of the food cup and $4 \mathrm{~cm}$ from the floor. Snout entries into the food cup were detected by a pair of infrared sensors mounted across the front of the food cup. Surveillance cameras located inside the surrounding shells were used to videotape mouse behavior.

After the final conditioning session, locomotor activity was assessed in an open-field apparatus. The open-field chamber $(43.2 \times 43.2 \mathrm{~cm})$ was composed of Plexiglas walls and was connected to a computer running Open Field Activity Software (Med Associates). The chamber was equipped with 16 photobeams mounted on the sides at two different heights to monitor locomotor activity.

On each of the first two training days, mice received 12 nonreinforced presentations of the panel light (10 s each) presented within the $32 \mathrm{~min}$ sessions (average intertrial interval was $2.75 \mathrm{~min}$ ). During the 10 subsequent daily conditioning sessions, mice received six trials consisting of light presentation (10 s), followed immediately by delivery of two $45 \mathrm{mg}$ food pellets. After the last day of conditioning, mice were placed individually in the open-field chamber and allowed to explore the chamber for $10 \mathrm{~min}$. Mouse locomotion was monitored, and the total distance traveled was recorded. Chambers were cleaned with Quatricide between testing each animal.

Behavioral observations. Orienting behavior was measured according to methods previously described (Holland, 1977; Chess and Bucci, 2006) and was defined as rearing on the hind legs with both forepaws off the ground. Grooming was not considered an instance of rearing, even if both forepaws were off the ground. Behavior was scored from videotapes every $1.25 \mathrm{~s}$ during the $5 \mathrm{~s}$ period preceding the CS (pre-CS), the $10 \mathrm{~s}$ during the CS, and the $5 \mathrm{~s}$ after CS presentation (post-CS). The index of response frequency was percent-orienting behavior, calculated as the number of times the subject was observed orienting to the light divided 
Table 1. Comparison of physiological properties and phasic cholinergic responsiveness in pyramidal neurons from different cortical layers and genetic backgrounds

\begin{tabular}{|c|c|c|c|c|c|c|c|}
\hline Genotype & Layer & $n$ & $\mathrm{RMP}(\mathrm{mV})$ & $\mathrm{R}_{\mathrm{N}}(\mathrm{M} \Omega)$ & Sag (\%) & "SK" response (mV) & Spike acceleration (\%) \\
\hline Wild type & $2 / 3$ & 15 & $-85 \pm 3^{\dagger}$ & $140 \pm 30^{\dagger}$ & $3 \pm 1^{\dagger}$ & $+0.4 \pm 0.5^{\dagger}$ & $+34 \pm 22^{\dagger}$ \\
\hline M1 KO & $2 / 3$ & 8 & $-84 \pm 2$ & $185 \pm 30^{*}$ & $3 \pm 1$ & $+0.3 \pm 0.5$ & $-10 \pm 13^{*}$ \\
\hline M3/M5 K0 & $2 / 3$ & 16 & $-85 \pm 3$ & $154 \pm 49$ & $4 \pm 3$ & $+0.6 \pm 1.0$ & $+22 \pm 13$ \\
\hline Wild type & 5 & 15 & $-80 \pm 2$ & $75 \pm 33$ & $15 \pm 3$ & $-2.3 \pm 0.8$ & $+75 \pm 43$ \\
\hline M1 K0 & 5 & 14 & $-81 \pm 2$ & $89 \pm 53$ & $14 \pm 5$ & $+0.1 \pm 0.2^{*}$ & $-1 \pm 8^{*}$ \\
\hline M3 K0 & 5 & 11 & $-80 \pm 3$ & $68 \pm 30$ & $17 \pm 5$ & $-2.1 \pm 1.1$ & $+52 \pm 47$ \\
\hline M5 K0 & 5 & 7 & $-81 \pm 2$ & $99 \pm 41$ & $10 \pm 4$ & $-2.4 \pm 1.2$ & $+43 \pm 40$ \\
\hline M3/M5 K0 & 5 & 7 & $-81 \pm 2$ & $82 \pm 23$ & $10 \pm 5$ & $-2.4 \pm 1.3$ & $+59 \pm 17$ \\
\hline
\end{tabular}

Comparison of physiological characteristics and phasic cholinergic responses at resting membrane potentials (SK response) or during current-evoked action potential firing (spike acceleration). Numbers in bold indicate $p<0.05$ for cholinergic-induced "SK" responses and spike acceleration (paired $t$ test). ${ }^{*} p<0.01$ compared with other groups of cells in the same cortical layer (Kruskal-Wallis test). ${ }^{\dagger} p<0.01$ when wild-type layer $2 / 3$ neurons are compared with wild-type layer 5 neurons (Mann-Whitney test). K0, Genetic knock-out for indicated mAChR subtype; Sag, percent voltage rectification at steady-state relative to peak potential reached during negative current injections.

by the total observations recorded during an observation period. Behavioral observations were conducted by a single primary observer who was blind to experimental condition. A subset of the behavioral sessions were scored a second time by a secondary observer to assess interrater reliability; the two observers agreed on $99 \%$ of $\sim 300$ joint observations. During the conditioned sessions, breaks in the photobeam located across the entry of the food cup were monitored by computer and used as a measure of conditioned responding.

Statistical analysis. Data for electrophysiological experiments are presented as mean \pm SD. Statistical analysis for unpaired samples used either a Mann-Whitney (two-tailed) or nonparametric ANOVA (Kruskal-Wallis test with a Dunn's multiple comparisons test). Comparisons of paired data used a Student's $t$ test for paired samples (two-tailed).

Statistical analysis of orienting behavior during nonreinforced presentations of the light was conducted using a repeated measures ANOVA (rANOVA) with Session as the within-subjects variable and Group (wild-type and M1 knockout) as the between subjects variable. During the conditioning sessions, the number of breaks in the beam placed across the front of the food cup were counted and averaged across the trials in each session. Group differences were analyzed using an rANOVA with Group as the between subjects variable and Session as the within-subjects variable. Group differences in locomotor activity were analyzed using an unpaired $t$ test. Correlations between locomotor activity in the open field and measures of conditioned responding were assessed by calculating Pearson correlation coefficients. An $\alpha$ level of 0.05 was used for all analyses.

\section{Results}

Phasic cholinergic responses in mouse neocortical pyramidal neurons

Whole-cell recordings were made from pyramidal neurons in layers $2 / 3$ and 5 of the dorsal $\mathrm{mPFC}$ from wild-type mice. These two populations have distinct physiological properties (supplemental Fig. 1, available at www.jneurosci.org as supplemental material; Table 1). Neurons in layer $2 / 3$ were more hyperpolarized than were neurons in layer 5 (mean RMPs were $-85 \pm$ 5 and $-81 \pm 2 \mathrm{mV}$ for neurons in layer $2 / 3$ and 5 , respectively;
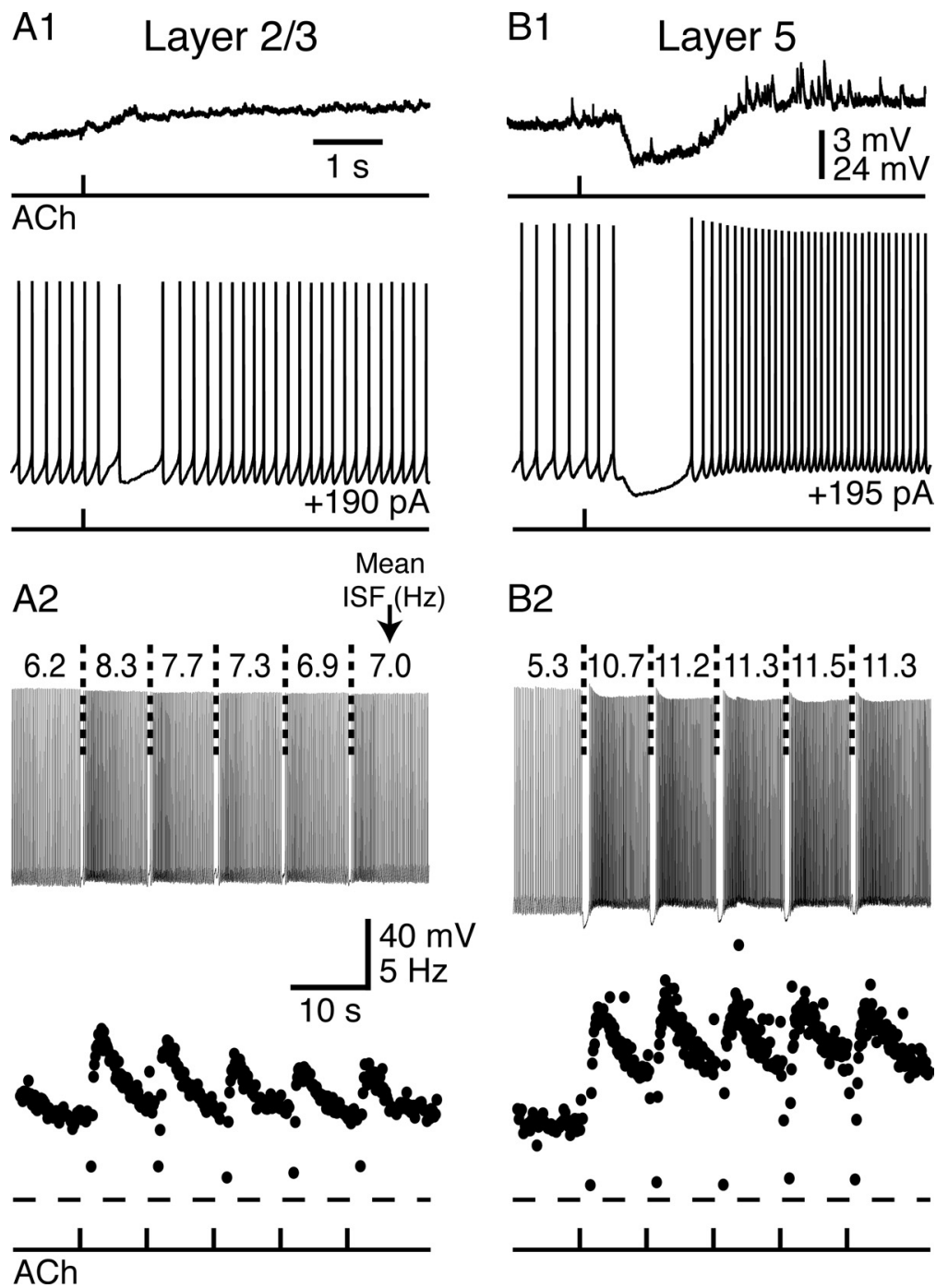

B2

Figure 1. Phasic cholinergic signaling in mouse neocortical pyramidal neurons. Shown are responses to $A C h(40 \mathrm{~ms})$ in pyramidal neurons from layers $2 / 3(\boldsymbol{A})$ and $5(\boldsymbol{B})$ of the mouse $\mathrm{mPFC}$. Top traces in $\boldsymbol{A} 1$ and $\boldsymbol{B} 1$ show responses to $A C h$ applications at the RMP. Bottom traces show responses to $A C h$ applications delivered during periods of current-induced action potential generation. Top traces in $\mathbf{A}$ and $\mathbf{B} \mathbf{2}$ show responses to repetitive applications of ACh (5 applications delivered at $8 \mathrm{~s}$ intervals) in the layer 2/3 neuron ( $\boldsymbol{A} \mathbf{2}$ ) and layer 5 neuron (B2) shown in $\boldsymbol{A} \mathbf{1}$ and $\boldsymbol{B}$ 1. Bottom graphs show the instantaneous spike frequencies for all spikes occurring in the electrical traces above. The level of $\mathrm{OHz}$ is indicated by dashed lines below the plots. ACh was applied at the times indicated in the bottom trace.

$n=8$ for each layer; $p<0.05)$. Superficial pyramidal neurons also had higher input resistances $\left(\mathrm{R}_{\mathrm{N}}\right)$ than did layer 5 neurons $\left(\right.$ mean $R_{N}$ was $146 \pm 42 \mathrm{M} \Omega$ in layer $2 / 3$ neurons vs $70 \pm 21 \mathrm{M} \Omega$ in layer 5 neurons; $p<0.001$ ) and exhibited reduced depolarizing 
"sag" potentials in response to hyperpolarizing current injection (indicative of the presence of hyperpolarization-activated nonspecific cation channels; mean sag was $3 \pm 3 \%$ in layer $2 / 3$ neurons vs $13 \pm 3 \%$ in layer 5 neurons; $p<0.001)$. Almost identical differences in these physiological properties were observed in independent groups of layer $2 / 3$ and 5 neurons ( $n=15$ for each group) used as controls in later experiments (see below and Table 1$)$.

Layer 5 and layer $2 / 3$ neurons also differed in their responsiveness to focally applied ACh (Fig. 1). ACh (100 $\mu \mathrm{M} ; 40 \mathrm{~ms})$ applied near the soma of pyramidal neurons in layer $2 / 3$ did not hyperpolarize neurons from their RMPs (mean change in membrane potential $900 \mathrm{~ms}$ after $\mathrm{ACh}$ application was $+0.7 \pm 0.8 \mathrm{mV} ; n=$ 8 ) and generated only modest increases in action potential frequency ("spike acceleration," see Materials and Methods) when delivered during sustained, current-induced periods of activity (mean spike acceleration was $+17 \pm 9 \% ; n=8 ; p<0.01$ ) (Fig. $1 A$ ). Although ACh failed to hyperpolarize layer $2 / 3$ pyramidal neurons at RMPs, ACh frequently $(>50 \%)$ induced transient decreases in firing rate when applied during ongoing action potential generation (Fig. $1 A$; see also Fig. 4). ACh application reduced the mean ISF from $6.0 \pm 1.4 \mathrm{~Hz}$ to a minimum ISF of $2.2 \pm 2.0 \mathrm{~Hz}(n=8)$, occurring just before the onset of spike acceleration (Fig. $1 A$ ).

However, ACh applied to pyramidal neurons in layer $5(n=8)$ produced hyperpolarizing responses from RMPs (mean response, $-2.4 \pm 1.3 \mathrm{mV} ; p<0.01$ ) and pronounced inhibition followed by spike acceleration $(+50 \pm 19 \%$; $p<0.01)$ when delivered during periods of action potential generation (Fig. $1 B$ ). ACh application decreased the mean ISF of layer 5 neurons from $5.8 \pm 1.2 \mathrm{~Hz}$ to a minimum ISF of $0.8 \pm 0.4 \mathrm{~Hz}$ (Fig. $1 B$ ), a minimum frequency significantly lower than that observed in layer $2 / 3$ neurons $(p<0.05)$. When ACh was applied repeatedly during periods of current-induced activity (five applications at $8 \mathrm{~s}$ intervals), ACh had only modest effects on action potential output in layer $2 / 3$ pyramidal neurons (Fig. $1 A$ ) but consistently generated transient inhibition followed by enhanced firing rates in layer 5 neurons (Fig. $1 B$ ). Inhibition of firing in layer 5 neurons had a mean duration of $1.68 \pm 0.86 \mathrm{~s}$, whereas transient increases in ISF decayed exponentially with a mean time constant of $5.4 \pm$ $2.3 \mathrm{~s}(n=8)$. Comparison of the magnitudes of ACh effects on RMPs and spike acceleration in neurons from layers $2 / 3$ and 5 demonstrate that the effects of ACh are significantly more robust in layer 5 pyramidal neurons ( $p<0.001$ for each). Similar layer-specific differences in cholinergic signaling were verified in additional neurons ( $n=15$ for each layer) used as controls for experiments comparing cholinergic signaling in neurons expressing different $\mathrm{mAChRs}$ (see below and Table 1).

Cholinergic inhibition of pyramidal neurons in the rat neocortex and hippocampus results from M1-like mAChR activation, inositol trisphosphate $\left(\mathrm{IP}_{3}\right)$-mediated calcium release, and subsequent activation of an SK-type calcium-activated potassium conductance (Gulledge and Stuart, 2005; Gulledge and Kawaguchi, 2007). To confirm that phasic cholinergic responses in mouse layer 5 neurons are mediated by muscarinic receptors, we bath-applied the mAChR antagonist atropine $(1 \mu \mathrm{M})$. Atropine blocked both hyperpolarizing responses to ACh at RMPs and spike acceleration following ACh applications during sustained action potential generation $(n=5)$ (Fig. $2 A$ ). Focal ACh application generated a mean hyperpolarization from RMPs of $-2.6 \pm 0.8 \mathrm{mV}$ (inhibitory response) and induced a $+68 \pm 45 \%$ increase in ISF (spike acceleration). In the presence of atropine, cholinergic inhibitory responses (mean "response" was $+0.5 \pm$ $0.2 \mathrm{mV}$ ) and spike acceleration (mean change in spike frequency was $-1 \pm 10 \%)$ were absent.
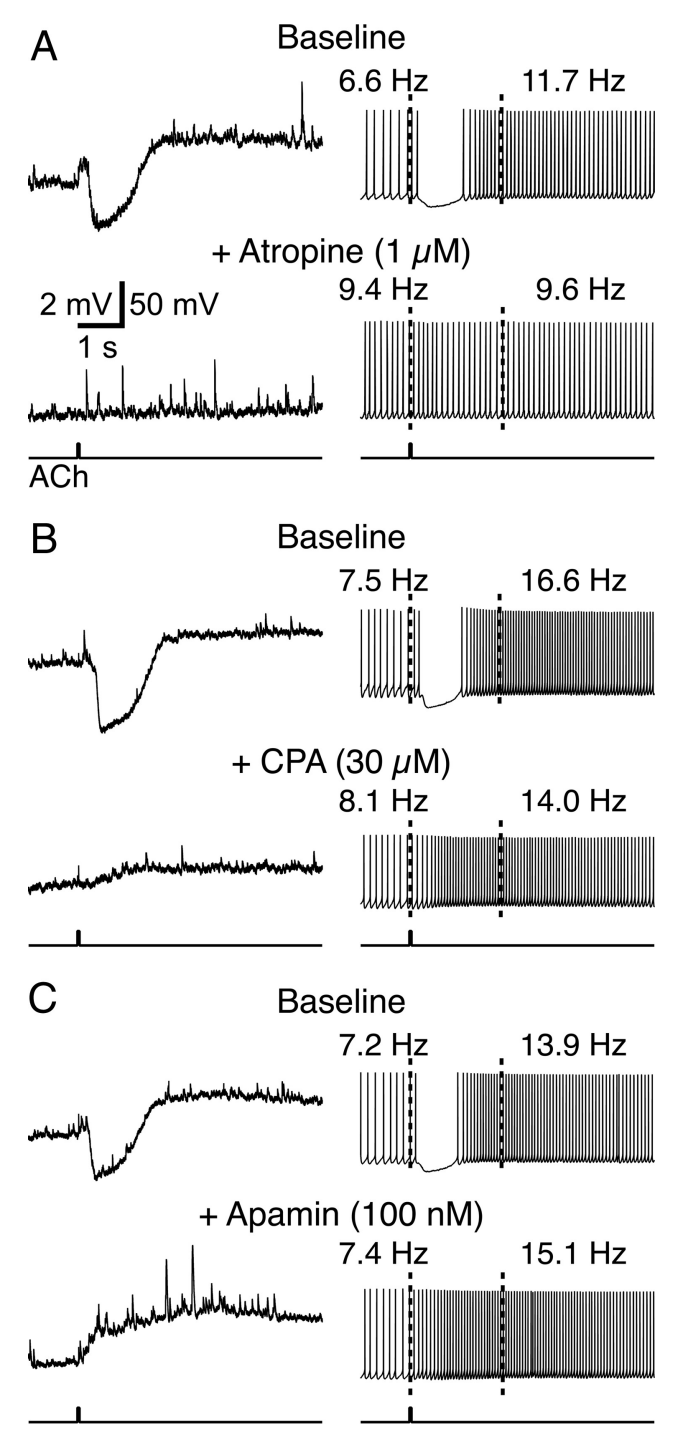

Figure 2. Mechanisms of phasic cholinergic inhibition in mouse layer 5 pyramidal neurons. $\boldsymbol{A}$, Top traces show baseline responses to ACh at the RMP (left) and during periods of action potential generation (right). Note that ACh hyperpolarizes the neuron from the RMP and induces inhibition followed by spike acceleration when applied during current-induced action potential generation. Bath application of the mAChR antagonist atropine (bottom traces) blocks both the excitatory and inhibitory effects of $A C h$. $\boldsymbol{B}$, In a different neuron, baseline cholinergic responses (top traces) are differentially affected by bath application of the SERCApump inhibitor CPA (30 $\mu \mathrm{m})$. CPA abolished phasic cholinergic inhibition but did not interfere with ACh-induced spike acceleration (bottom traces). C, Bath application of apamin (100 nm), a specific blocker of SK-type calcium-activated potassium channels, also preferentially blocks phasic cholinergic inhibition while facilitating spike acceleration.

To confirm that muscarinic inhibition requires calcium release from intracellular stores, we focally applied ACh to layer 5 pyramidal neurons before and after bath application of cyclopiazonic acid (CPA; $30 \mu \mathrm{M}$ ), an inhibitor of calcium store filling (Fig. 2B). CPA abolished inhibitory responses to ACh (responses at RMPs were reduced from $-3.7 \pm 1.5 \mathrm{mV}$ in baseline conditions to $+1.3 \pm 0.7 \mathrm{mV}$ in CPA; $p<0.01 ; n=5$ ) but had no effect on spike acceleration (mean accelerations were $+75 \pm 40 \%$ under baseline conditions and $+120 \pm 97 \%$ following CPA application; $p=0.38)$. These data demonstrate that cholinergic inhibition, but not excitation, depends upon calcium release from intracellular stores.

Finally, we confirmed that cholinergic inhibition in the mouse cortex is mediated by activation of an SK-type calcium- 
activated potassium conductance by bath-applying the selective SK channel blocker apamin (Fig. 2C). As was found with CPA, apamin (100 nM) abolished cholinergic inhibition $(n=5)$, replacing hyperpolarizing responses from RMPs with depolarizing responses (mean baseline response was $-3.0 \pm 0.9 \mathrm{mV}$, whereas mean response in apamin was $+1.9 \pm 1.3 \mathrm{mV} ; p<0.01)$. On the contrary, spike acceleration was enhanced by the presence of apamin (mean spike accelerations were $+44 \pm 29$ and $+92 \pm$ $33 \%$ under baseline and apamin conditions, respectively; $p<0.05)$. Together, these data demonstrate that cholinergic inhibition in the mouse cortex uses the same signaling cascades and ionic mechanisms (calcium release from intracellular stores and SK channel activation) that mediate phasic cholinergic effects in the rat cortex (Gulledge and Stuart, 2005; Gulledge and Kawaguchi, 2007).

\section{M1 receptors are necessary and sufficient for phasic \\ cholinergic signaling}

To determine the relative contributions of M1-like mAChRs in modulating neocortical pyramidal neurons, we compared responsiveness to focal ACh applications in layer 5 pyramidal neurons from wild-type mice and neurons from mice lacking specific M1-like mAChR subunits (M1, M3, and/or M5 receptors). In neurons from wild-type animals $(n=15)$ and neurons from mice lacking M3 $(n=11)$, M5 $(n=7)$, or both M3 and M5 receptors $(n=7)$, transient ACh applications generated hyperpolarization from RMPs and biphasic responses (spike inhibition followed by spike acceleration) when delivered during periods of current-induced action potential generation (Fig. 3, Table 1). In contrast, ACh had no effect on the excitability of pyramidal neurons from animals lacking M1 receptors $(n=14 ; p<0.001$ for both inhibitory and excitatory cholinergic responses in M1-lacking neurons when compared with responses in neurons from wild-type and other mAChR knock-out animals; Kruskal-Wallis test).

Although ACh had only modest effects on the excitability of layer $2 / 3$ pyramidal neurons, we tested whether cholinergic effects in these cells might also be mediated by M1 receptors (Fig. 4). Phasic ACh applications to wild-type layer $2 / 3$ neurons $(n=$ 15) generated small depolarizations from RMPs and weak, inhibitory-then-excitatory responses when delivered during periods of action potential generation (Fig. 4A, Table 1). When ACh was focally applied to layer $2 / 3$ neurons from M1-lacking mice (Fig. $4 B$, Table 1), neither transient inhibition nor spike acceleration was observed. However, ACh applications transiently inhibited action potential firing and induced spike acceleration in neurons from M3/M5 double-knock-out animals (Fig. $4 C$, Table 1). When applied at RMPs, focally applied ACh did not generate hyperpolarizing responses in any layer $2 / 3$ neurons, regardless of genotype (Fig. 4, Table 1). These data from additional wild-type and $\mathrm{mAChR}$-lacking neurons further demonstrate that phasic cholinergic signaling is less robust in superficial pyramidal neurons and that the cholinergic effects that do exist (e.g., modest spike acceleration) are mediated exclusively by M1-like mAChRs.

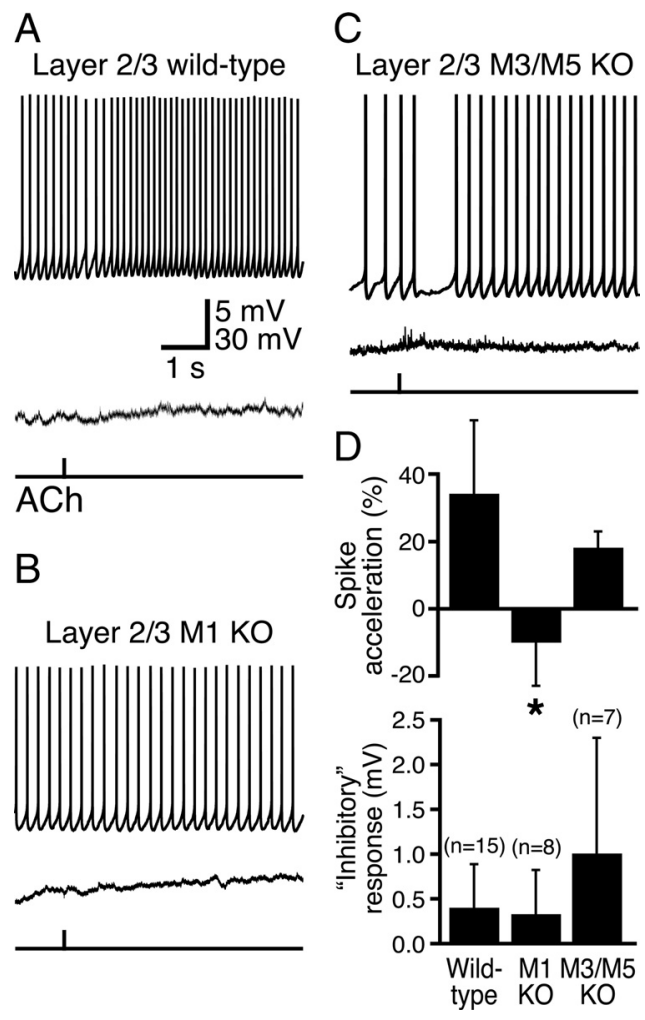

Figure 4. M1 receptors mediate phasic cholinergic signaling in superficial pyramidal neurons. $A-C$, Responses to $A C h$ at RMPs (bottom traces) and during action potential generation (top traces) in layer 2/3 pyramidal neurons from wild-type mice $(\boldsymbol{A})$ and mice lacking M1 $(\boldsymbol{B})$ or M3 and M5 $(\boldsymbol{C})$ receptors. $\boldsymbol{D}$, Summary comparisons of inhibitory and excitatory cholinergic responses in layer $2 / 3$ pyramidal neurons from mice with differing $\mathrm{mAChR}$ expression. Note that cholinergic "inhibitory responses" were depolarizing rather than hyperpolarizing. Cholinergic spike acceleration was absent only in M1-lacking neurons. K0, Knock-out. 

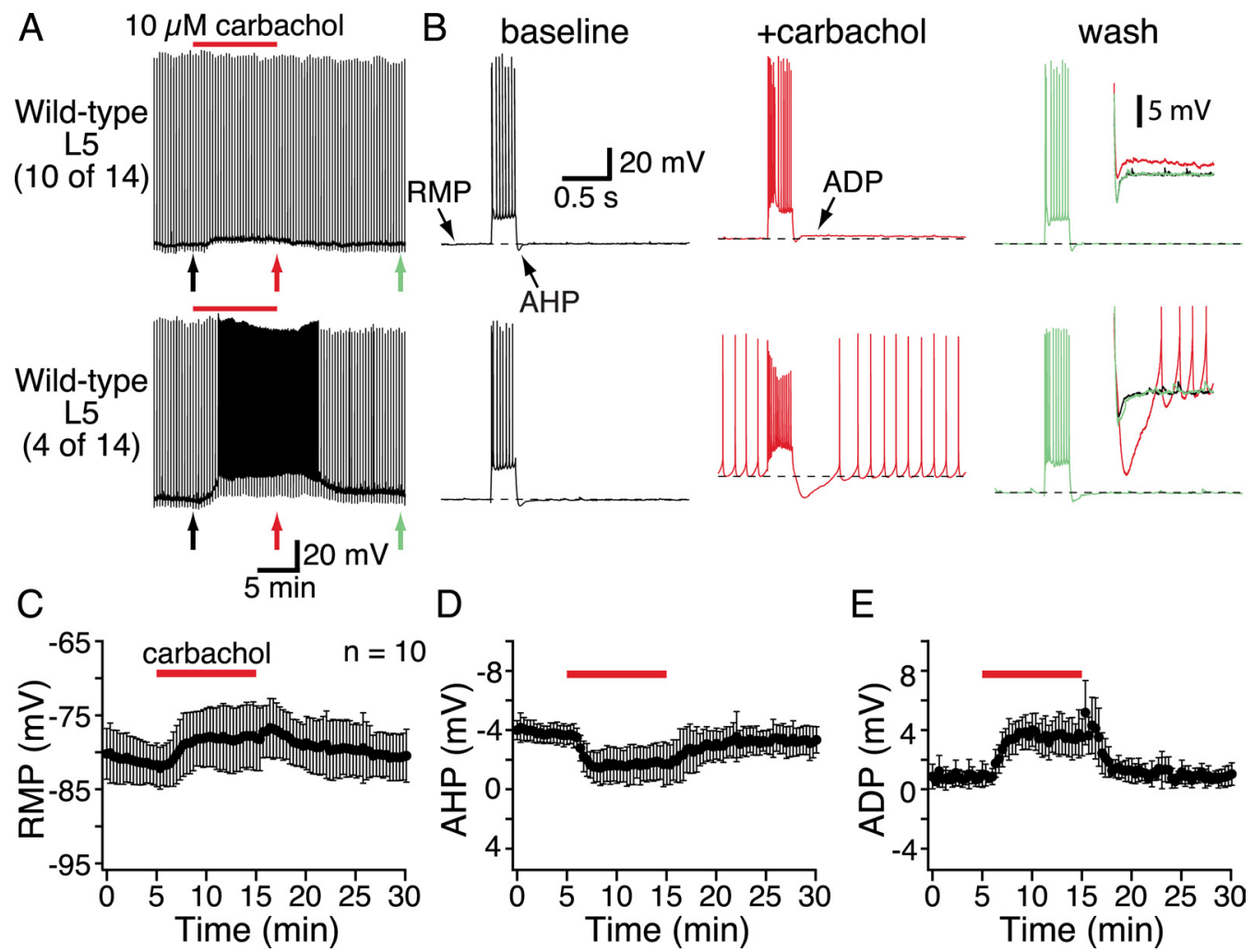

Figure 5. Tonic cholinergic excitation in layer 5 pyramidal neurons. $A$, Chart recordings of the membrane potentials of two layer 5 pyramidal neurons from wild-type mice. Periodic current steps $(450 \mathrm{pA} ; 250 \mathrm{~ms})$ delivered every $20 \mathrm{~s}$ produced short bursts of action potentials. Individual responses to specific current injections (indicated by colored arrows) are shown at a faster timescale in $\boldsymbol{B}$. In most cells (10 of 14), carbachol application (10 $\mu \mathrm{m} ; 10 \mathrm{~min}$ ) generated subthreshold changes in the RMP, suppressed the AHP, and generated an ADP. In other neurons (4 of 14), carbachol application excited neurons sufficiently to generate spontaneous action potentials (bottom trace in $\boldsymbol{A}$ ). $\boldsymbol{B}$, Individual responses (indicated by arrows under chart recordings in $\boldsymbol{A}$ ) to current injections in baseline conditions (black traces, left), following 10 min exposure to carbachol (red traces, middle), and after 15 min of wash (green traces, right). Expanded views of the AHP/ADP complexes following these current steps are superimposed and inset to the far right. $\boldsymbol{C}-\boldsymbol{E}$, Plots of RMP $(\boldsymbol{C})$, AHP $(\boldsymbol{D})$, and ADP $(\boldsymbol{E})$ amplitudes over time from experiments in which carbachol generated subthreshold excitation $(n=10)$.

When combined with data from layer 5 neurons, our results suggest that M1 receptors are both necessary and sufficient for phasic cholinergic signaling in neocortical pyramidal neurons.

\section{$\mathrm{M} 1$ and $\mathrm{M} 3$ receptors are involved in tonic cholinergic signaling}

M1-like mAChRs are also responsible for the increases in excitability observed during tonic cholinergic stimulation of cortical pyramidal neurons, and both phasic and tonic cholinergic signaling can occur simultaneously in the same neuron (Gulledge and Stuart, 2005; Gulledge et al., 2007). We tested the receptor subtypes involved in generating tonic cholinergic excitation by bathapplying the cholinergic agonist carbachol (10 $\mu \mathrm{M}$ for $10 \mathrm{~min})$ to layer 5 pyramidal neurons from wild-type mice and mice lacking specific mAChRs. As shown in Figure 5, periodic current injections in wild-type neurons $(\sim 450 \mathrm{pA}, 250 \mathrm{~ms}$; delivered at 0.05 $\mathrm{Hz}$ ) generated brief trains of action potentials that were followed by membrane repolarization beyond the initial RMP, an event known as the AHP. Layer 5 pyramidal neurons from wild-type animals exhibited three reversible responses to bath-applied carbachol: depolarization of the RMP, a reduction in the AHP following depolarizing current injections, and the appearance of an ADP potential. At $10 \mu \mathrm{M}$, carbachol excited approximately onethird of wild-type neurons ( 4 of 14) to the point of spontaneous action potential generation (Fig. $5 A, B$, bottom traces). Since spontaneous activity complicates accurate measurements of RMPs, AHPs, and ADPs, data for these parameters were analyzed only in cells showing subthreshold effects of carbachol $(n=10)$ (Fig. 5, Table 2). Carbachol reversibly depolarized wild-type neurons, depressed AHPs, and revealed ADPs (Table 2). These effects of bath-applied carbachol in the mouse cortex are consistent with carbachol effects observed in the rat (Gulledge and Stuart, 2005).

To test whether M1 receptors are responsible for tonic cholinergic signaling, we bath-applied carbachol to layer 5 pyramidal neurons from mice lacking M1 receptors $(n=10)$ (Fig. 6, Table 2). Carbachol failed to induce spontaneous activity in any of these neurons and had no significant effects on RMPs $(p=0.14)$, AHPs $(p=0.29)$, or ADPs $(p=0.90)$. These data demonstrate that M1 receptors are necessary for tonic cholinergic signaling. To test whether M1 receptors are also sufficient for tonic cholinergic excitation of layer 5 pyramidal neurons, we repeated experiments in neurons from compound-mutant mice lacking both M3 and M5 mAChRs (Fig. 7, Table 2). As was found in wild-type neurons, bath-applied carbachol $(10 \mu \mathrm{M})$ excited a proportion of M3/M5-lacking layer 5 pyramidal neurons (4 of 15 neurons) to the point of spontaneous action potential generation (Fig. 7A,B). Analysis of cholinergic responses in the 11 neurons showing subthreshold excitation revealed significant carbachol-induced depolarization and ADP generation (Table 2). However, in M3/ M5-lacking neurons, carbachol failed to decrease the amplitude of the AHP (mean change, $-0.1 \pm 1.4 \mathrm{mV} ; p=0.83$ ). These data demonstrate M1 receptors to be necessary for tonic cholinergic signaling but sufficient only for ACh-induced depolarization and 
Table 2. Comparison of tonic cholinergic responses in pyramidal neurons expressing different $m A C h R$ subunits

\begin{tabular}{|c|c|c|c|c|c|}
\hline Genotype & Layer & $n$ & $\Delta \mathrm{RMP}(\mathrm{mV})$ & $\Delta$ AHP amplitude (mV) & $\Delta$ ADP amplitude (mV) \\
\hline Wild type & $2 / 3$ & 11 & $+1.4 \pm 3.3$ & $-1.2 \pm 1.1$ & $+0.7 \pm 0.7$ \\
\hline M1 K0 & $2 / 3$ & 9 & $-1.0 \pm 1.6^{*}$ & $-0.7 \pm 0.7$ & $+0.2 \pm 0.4$ \\
\hline Wild type & 5 & 10 & $+3.9 \pm 2.1$ & $-1.9 \pm 1.1$ & $+2.6 \pm 1.2$ \\
\hline M1 K0 & 5 & 10 & $+0.9 \pm 1.7^{*}$ & $+0.3 \pm 0.8^{*}$ & $-0.0 \pm 0.6^{*}$ \\
\hline M3 K0 & 5 & 9 & $+3.3 \pm 2.9$ & $+0.4 \pm 0.9^{*}$ & $+1.8 \pm 1.2$ \\
\hline M5 K0 & 5 & 7 & $+5.0 \pm 2.7$ & $-2.2 \pm 1.8$ & $+2.9 \pm 2.0$ \\
\hline M3/M5 K0 & 5 & 11 & $+5.3 \pm 2.8$ & $-0.1 \pm 1.4^{*}$ & $+1.8 \pm 0.6$ \\
\hline
\end{tabular}

Cholinergic responses evoked by bath-applied carbachol (10 $\mu \mathrm{m}$ for $10 \mathrm{~min}$ ). Changes in RMP, AHP, and ADP amplitudes were measured at the end of carbachol treatment and relative to values measured in baseline conditions. Bold numbers indicate $p<0.05$ for carbachol effects on RMP and/or AHP and ADP amplitudes. Asterisks indicate $p<0.01$ when compared to wild-type neurons in the same layer. K0, genetic knock-out for indicated mAChR subtype.
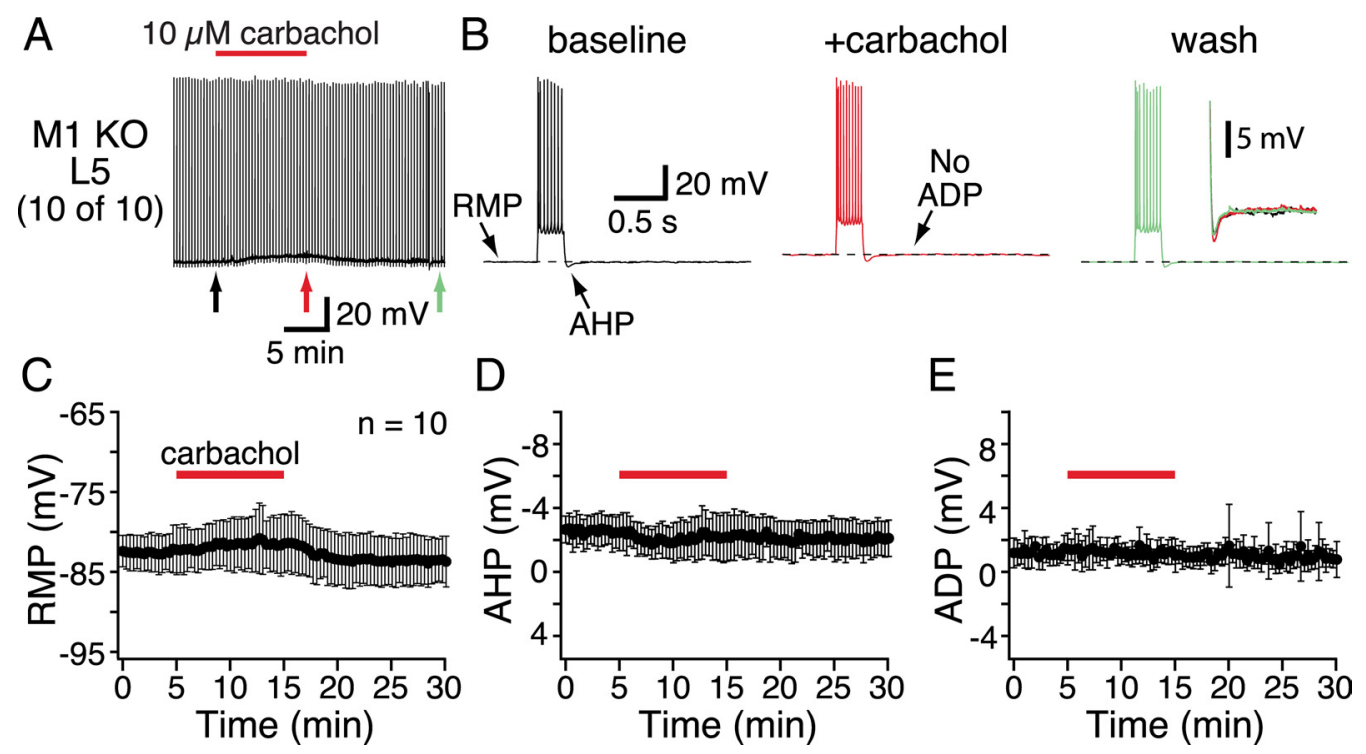

Figure 6. Bath-applied carbachol does not excite layer 5 pyramidal neurons from M1 knock-out mice. $A$, Chart recording of the membrane potential of a layer 5 pyramidal neuron from a mouse lacking M1 receptors. Current steps delivered at 20 s intervals generated brief periods of activity. Carbachol application failed to generate spontaneous activity in any M1-lacking neurons. $\boldsymbol{B}$, Individual responses to current injections delivered at the times indicated by arrows in $\boldsymbol{A}$, shown at a faster timescale. Expanded views of the AHPs are superimposed and inset to the far right. $\boldsymbol{C}-\boldsymbol{E}$, Plots of $\operatorname{RMP}(\boldsymbol{C}), \operatorname{AHP}(\boldsymbol{D})$, and $\operatorname{ADP}(\boldsymbol{E})$ amplitudes over time from experiments on M1-lacking layer 5 neurons $(n=10)$. K0, Knock-out.

ADP genesis. Cholinergic reduction of AHPs requires additional activation of at least one other M1-like mAChR.

To clarify the relative roles for M3 and M5 receptors in AHP reduction, we bath-applied carbachol to layer 5 pyramidal neurons lacking either M3 $(n=12)$ or M5 $(n=7)$ receptors alone (Fig. 7D,E, Table 2). In M3-lacking neurons, 3 of 12 neurons were excited to the point of generating spontaneous action potentials (data not shown). In the remaining nine neurons (Fig. 7D), bathapplied carbachol depolarized neurons and enhanced ADPs (Table 2). However, carbachol failed to reduce the amplitude of AHPs in M3-lacking neurons (mean change was $+0.4 \pm 0.9 \mathrm{mV}$; $p=0.36$ ). Neurons lacking only M5 receptors (Fig. 7E) showed normal responsiveness to bath-applied carbachol, which depolarized neurons, reduced their AHPs, and generated ADPs $(n=7$; $p<0.05$ for each parameter; Table 2). Thus, M5 receptors do not appear to be necessary for tonic cholinergic signaling in cortical pyramidal neurons, whereas both M3 and M1 mAChRs are necessary for carbachol-induced suppression of the AHP.

We next tested for tonic cholinergic effects in layer $2 / 3$ pyramidal neurons (Fig. 8). Bath application of carbachol $(10 \mu \mathrm{M})$ to superficial pyramidal neurons from wild-type animals $(n=11)$ had mixed effects on RMPs (mean change in RMP was $+1.4 \pm$ $3.3 \mathrm{mV} ; p=0.19)$, but decreased AHP amplitudes $(p<0.01)$ and enhanced ADPs $(p<0.01)$ (Table 2). In these neurons (Fig. $8 C$ ) and in layer $2 / 3$ neurons from M1-lacking mice (see below), we observed a slow, time-dependent decrease in AHP amplitude that was not apparent in layer 5 pyramidal neurons and which greatly exaggerated measurements of cholinergic reduction of the AHP. However, the pooled data show a component of AHP suppression corresponding to the presence of carbachol (Fig. $8 C$ ).

To test whether tonic cholinergic effects in layer $2 / 3$ pyramidal neurons are mediated by $\mathrm{M} 1$ receptors, we repeated experiments using neurons from M1 knock-out mice. M1-lacking layer 2/3 pyramidal neurons did not show any significant changes in RMPs or ADP amplitudes (Fig. 8D, Table 2), whereas changes in AHPs following carbachol application $(p<0.05)$ likely reflect only the slow time-dependent reduction of the AHP, because they fail to show any increase in amplitude during 15 min of wash. Together, these data suggest that the modest cholinergic effects observed in superficial pyramidal neurons, although less pronounced than those in layer 5, also depend upon M1 receptors.

\section{Tonic-like cholinergic effects generated by phasic} mAChR stimulation

Although studies examining cholinergic modulation of neuron excitability have often used tonic stimulation with bath-applied agonists such as carbachol (Schwindt et al., 1988; Williams and Constanti, 1988; Halliwell, 1989; Barkai and Hasselmo, 1994; Kawaguchi, 1997; Tang et al., 1997; Haj-Dahmane and Andrade, 1998), we asked whether shorter periods of exposure to ACh might also induce changes in RMPs and in AHP and ADP ampli- 


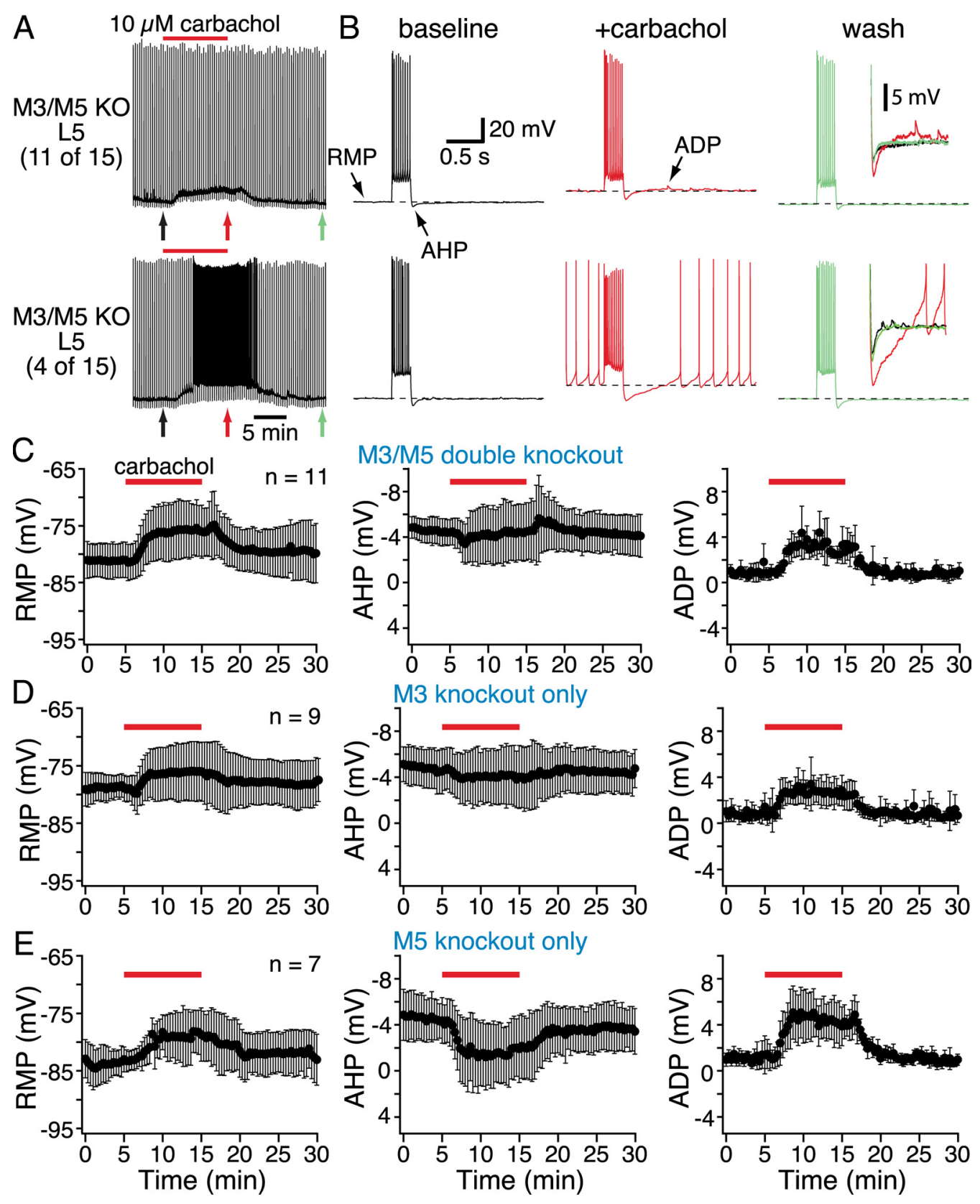

Figure 7. Effects of bath-applied carbachol on layer 5 pyramidal neurons lacking $M 3$ and/or $M 5$ receptors. $A$, Continuous chart recordings of the membrane potentials of two layer 5 pyramidal neurons from mice lacking both M3 and M5 receptors. Brief current steps delivered at 20 s intervals generated short periods of activity. Carbachol induced spontaneous activity in 4 of 15 neurons (bottom chart recording in $\boldsymbol{A}$ ). $\boldsymbol{B}$, Individual responses to current injections shown at a faster timescale, with expanded views of the AHPs and ADPs superimposed and inset to the far right. $C-\boldsymbol{E}$, Plots of RMP (left), AHP (middle), and ADP (right) amplitudes over time from data pooled from neurons lacking M3 and M5 receptors (C), M3 receptors alone (D), or M5 receptors alone (E). Note that carbachol depolarized the RMPs and enhanced ADPs but failed to modulate AHPs in mice lacking M3 receptors. K0, Knock-out.

tudes in layer 5 pyramidal neurons (see also McCormick and Prince, 1986). To test this, we focally applied a series of three ACh pulses $(100 \mathrm{~ms}$ each at $0.5 \mathrm{~Hz})$ to wild-type layer 5 pyramidal neurons $(n=6)$. Since inhibitory cholinergic responses rundown within three applications when ACh is applied repetitively at RMPs (Gulledge et al., 2007), we were able to deliver brief current injections ( $250 \mathrm{~ms} ; \sim 450 \mathrm{pA}$ ) to neurons immediately after phasic ACh applications without direct interaction between inhibitory cholinergic responses and current-step-induced voltage responses (Fig. 9A). We then compared RMPs, AHP amplitudes, and ADP amplitudes in baseline conditions and immediately (500 ms) following three ACh applications to determine whether brief exposure to ACh can mimic tonic cholinergic excitation.
Exposure to ACh depolarized RMPs (mean change, $+2.3 \pm 1.1$ $\mathrm{mV} ; n=6 ; p<0.05$ ) and increased ADP amplitudes (mean increase in ADP amplitude, $+1.8 \pm 0.8 \mathrm{mV} ; p<0.05$ ). Brief ACh applications also modulated the AHP (Fig. 9D), albeit in the opposite direction than observed during tonic carbachol stimulation. Instead of suppressing the AHP, brief exposure to a series of ACh applications enhanced the AHP by $1.9 \pm 0.9 \mathrm{mV}(p<0.05)$.

To confirm a role for $\mathrm{M} 1$ receptors in generating tonic-like cholinergic effects following transient ACh applications, we repeated experiments in layer 5 neurons from M1-lacking $(n=6)$ and M3-lacking $(n=10)$ mice. Focal applications of ACh failed to generate any change in the RMP of M1-lacking neurons ( $p=$ 0.56 ), and no changes were observed in the amplitudes of the 

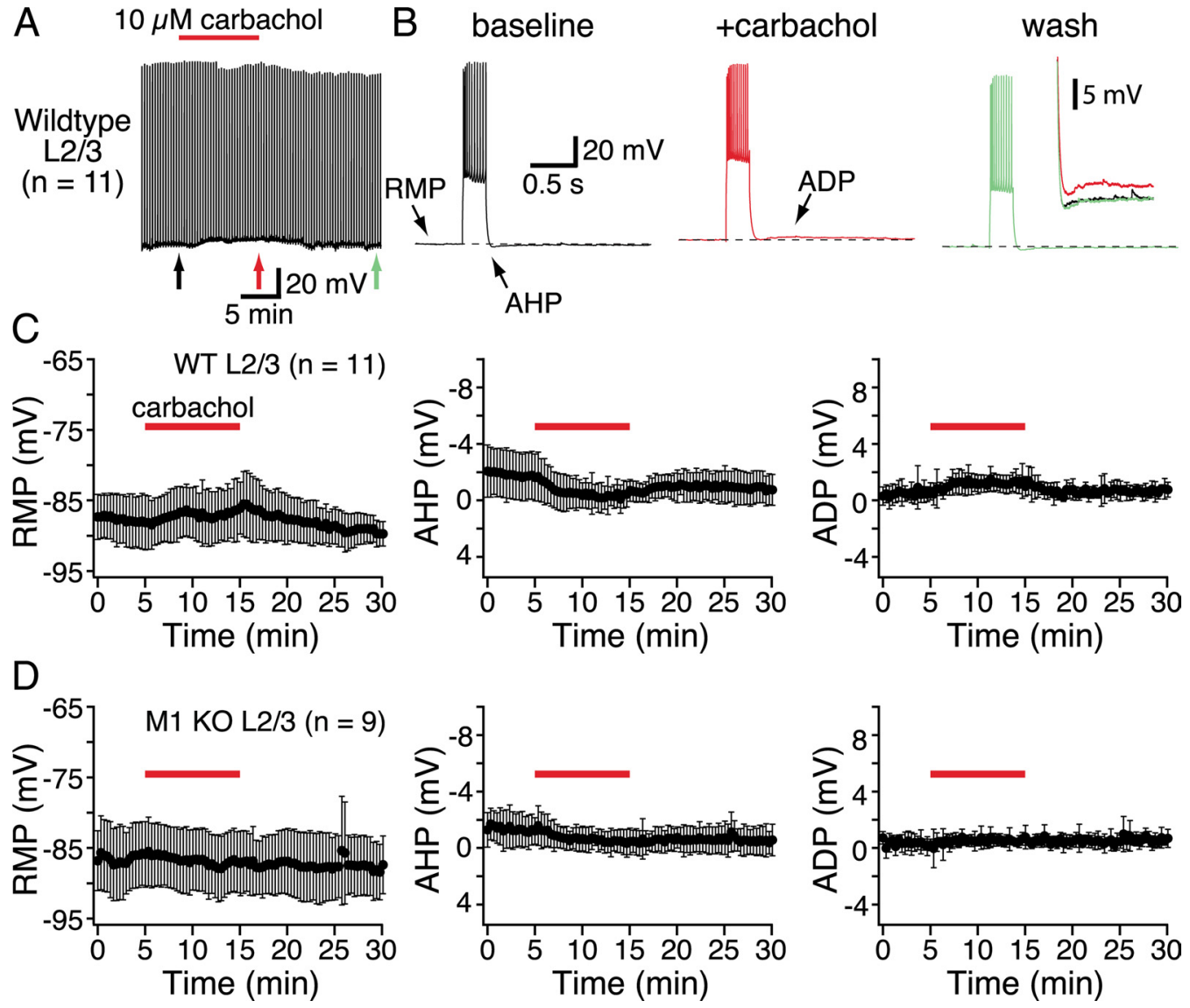

Figure 8. Layer 2/3 pyramidal neurons exhibit only modest M1-mediated responses to tonic cholinergic stimulation. $A$, Chart recording of the membrane potential of a wild-type layer $2 / 3$ pyramidal neuron. Carbachol was bath applied for $10 \mathrm{~min}$, as indicated. $\boldsymbol{B}$, Individual responses to current injections (indicted by colored arrows in $\boldsymbol{A}$ ) shown at a faster timescale, with expanded views of AHPs and ADPs superimposed and inset to the far right. C, Plots of the amplitudes of RMPs (left), AHPs (middle), and ADPs (right) over time for pooled data from experiments in wild-type (WT) layer 2/3 neurons $(n=11)$. D, Summary data of RMPs, AHPs, and ADPs from similar experiments conducted using M1-lacking layer $2 / 3$ pyramidal neurons $(n=9)$. The modest effects of carbachol evident in wild-type neurons are absent in M1-lacking neurons. K0, Knock-out.

$\operatorname{AHP}(p=0.31)$ or $\operatorname{ADP}(p=0.56)$ following brief currentinduced activity (Fig. 9B,C). However, M3-lacking neurons showed significant depolarization, AHP enhancement, and ADPgenesis (Fig. 9B,C; $p<0.01$ for each parameter). These data confirm a central role for $\mathrm{M} 1$ receptors in generating tonic cholinergic effects.

Why do phasic ACh applications enhance, rather than suppress, the AHP in neurons expressing M1 receptors? One possibility is that AHPs from depolarized RMPs (as occurs following ACh applications) are larger in amplitude as a result of greater driving force for the potassium conductance mediating the AHP. However, we found no significant differences in AHP amplitudes when neurons were depolarized by $\sim 3 \mathrm{mV}$ with somatic current injection ( $n=11$; data not shown). Another possibility is that ACh-induced calcium release from intracellular calcium stores acts synergistically with calcium entry through spike-activated voltage-gated calcium channels to enhance AHP amplitudes. To test this hypothesis, in a separate set of experiments, we transiently applied ACh to neurons before and after bath-applying apamin (100 nM) to block SK-type potassium channels (Fig. 9D). In baseline conditions, three ACh applications enhanced AHPs from $-5.2 \pm 1.1$ to $-6.4 \pm 1.8 \mathrm{mV}(n=7 ; p<0.05)$. Bath application of apamin slightly, yet significantly, decreased baseline AHP amplitudes by $16 \pm 14 \%(p<0.05)$, indicating that SK channels normally make only a small contribution to AHP generation. However, in the presence of apamin, ACh failed to en- hance AHP amplitudes, but rather reduced them to $-3.1 \pm 1.6$ $\mathrm{mV}(p<0.001)$, an amount of AHP suppression $(+1.5 \pm 0.5$ $\mathrm{mV}$ ) comparable to that generated by bath-applied carbachol $(1.9 \pm 1.1 \mathrm{mV}$; Table 2). Thus, phasic cholinergic stimulation allows SK conductances to facilitate AHPs that are otherwise suppressed by tonic $\mathrm{mAChR}$ activation.

These results demonstrate that cholinergic depolarization and ADP genesis do not require prolonged exposure to agonists but that cholinergic effects on the AHP depend on the time course of agonist exposure. They also demonstrate that tonic and phasic cholinergic effects are linked even at the initial stage of signal transduction by activating a common pool of M1 receptors.

\section{Tonic cholinergic effects do not depend on increased action potential generation}

A potentially confounding factor in the above experiments is the tendency for cholinergic agonists to modulate the number of spikes generated by depolarizing steps (Figs. 5-7). To control for changes in action potential number during cholinergic stimulation, we conducted new experiments using trains of 10 action potentials generated with brief (2-3 ms), high-amplitude (4 nA) current injections delivered at $40 \mathrm{~Hz}$ (Fig. 10A). Bath-applied carbachol (5 min) significantly depolarized wild-type neurons by $4.9 \pm 1.9 \mathrm{mV}(p<0.0001)$, suppressed AHPs by $1.7 \pm 0.7 \mathrm{mV}$ $(p<0.0001)$, and enhanced ADPs by $2.5 \pm 1.0 \mathrm{mV}(p<0.0001)$ 

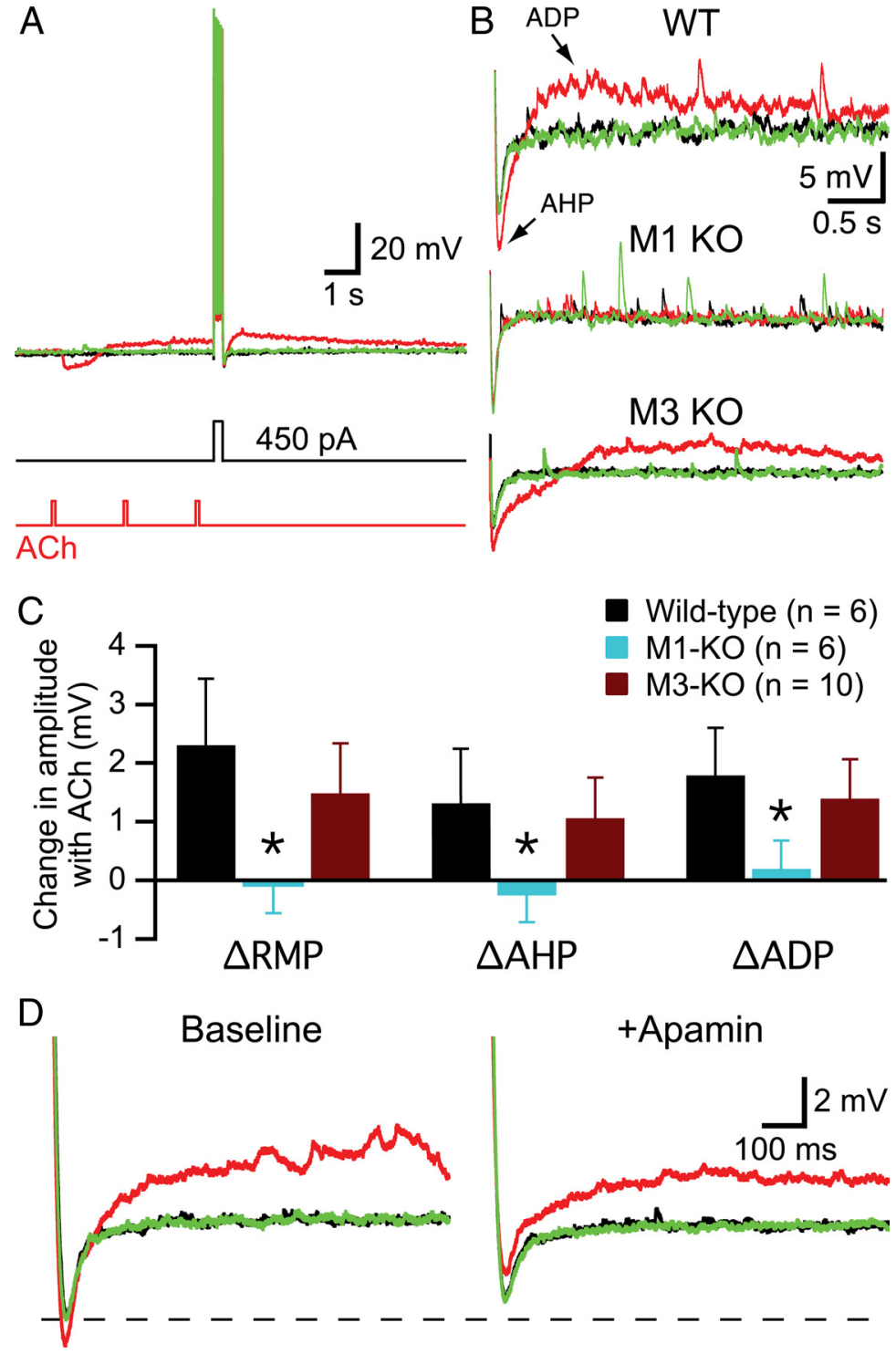

Figure 9. Phasic ACh applications mimic tonic effects of carbachol by depolarizing layer 5 pyramidal neurons and generating ADPs following brief spike trains. A, Superimposed traces showing responses to a brief ( $250 \mathrm{~ms}$ ) current injection (450 pA) in baseline conditions (black), after three brief applications of $\mathrm{ACh}$ (red), and after $20 \mathrm{~s}$ of wash (green). $B$, Expanded view of AHPs and ADPs in neurons from wild-type (WT; top), M1 knock-out (middle), and M3 knock-out (bottom) mice. C, Summary graph comparing mean changes in RMPs, and AHPs and ADP amplitudes following focal ACh application in wild-type and mAChR-lacking neurons. Note that ACh application depolarized wild-type and M3-lacking neurons and increased their ADPs but also increased the amplitudes of their AHPs. $D$, AHPs and ADPs recorded in a wild-type neuron under baseline conditions (black), following brief exposure to $\mathrm{ACh}$ (red), and after $20 \mathrm{~s}$ of wash (green) before (left) and after (right) bath application of the SK channel blocker apamin (100 nM). Apamin slightly reduced baseline AHP amplitudes (dashed line) but converted cholinergic enhancement of the AHP into AHP suppression. K0, Knock-out.

with ADP amplitudes in wild-type or M3 lacking neurons; Kruskal-Wallis test).

Similar tonic-like cholinergic effects were observed when controlled spike trains were preceded by three focal applications of ACh (delivered at $0.5 \mathrm{~Hz}$ ) (Fig. $10 D-F)$. ACh depolarized wild-type $(n=$ 9) and M3-lacking $(n=9)$ neurons $(p<$ 0.01 for each), enhanced AHP amplitudes ( $p<0.01$ for wild type; $p<0.05$ for M3lacking neurons), and generated significant ADPs ( $p<0.01$ for each). However, M1-lacking neurons $(n=9)$ showed no significant changes in membrane potentials $(p=0.73)$ or AHP amplitudes $(p=$ 0.74) following ACh applications but did exhibit small, yet significant $(p<0.01)$, $\mathrm{ADPs}$ following $\mathrm{ACh}$ applications that were significantly smaller than those generated by ACh application to wild-type or M3-lacking neurons ( $p<0.01$; KruskalWallis test).

Our experiments using controlled spike trains confirm a central role for M1 receptors in tonic cholinergic signaling that is independent of changes in neuronal output (action potential generation). They also confirm that both M1 and M3 receptors are necessary for tonic cholinergic suppression of the AHP and suggest M3 and/or M5 receptors may provide limited facilitation of the ADP under some conditions.

\section{M1 receptors contribute to cue detection behaviors}

During cue detection tasks, ACh is transiently released into the $\mathrm{mPFC}$, and the phasic rise in prefrontal $\mathrm{ACh}$ is predictive of successful behavioral performance (Parikh et al., 2007). Our physiological data indicate that transient cortical ACh release will modulate the activity of pyramidal neurons primarily via activation of M1 receptors. Therefore, if cholinergic modulation of pyramidal neurons is important for cue detection, M1-lacking mice should show behavioral deficits. To test this hypothesis, we trained mice in a simple conditioning procedure in which a visual stimulus (a light) was presented re-

(Fig. 10B). A similar level of depolarization and ADP enhancement was observed in M3-lacking neurons $(p<0.001$ for each) (Fig. $10 B, C$ ). However, carbachol failed to suppress the AHPs of M3-lacking neurons $(n=9 ; p=0.42)$ and had no effects on membrane potentials or AHPs in M1-lacking neurons ( $n=9 ; p=0.25$ for each). However, carbachol did generate a very small, yet statistically significant $(p<0.05)$ ADP in M1-lacking neurons that was almost an order of magnitude smaller than those generated in wild-type or M3-lacking neurons (mean amplitude was only $0.35 \pm 0.27 \mathrm{mV}$ in M1-lacking neurons, compared with $2.5 \pm 1.0$ and $2.1 \pm 1.0 \mathrm{mV}$ in wild-type and M3-lacking neurons, respectively; $p<0.001$ when compared peatedly over two sessions and not reinforced. Rodents initially orient to the light by rearing up on the hind legs to face the stimulus ("rearing behavior"; Holland, 1977, 1984), a behavior that is thought to reflect effortful processing or detection of the stimulus (Kaye and Pearce, 1984; Gallagher et al., 1990; Lang et al., 1997). When the light is subsequently paired with food reward during the second phase of the task, mice learn to associate the light with food and exhibit conditioned food-cup behavior during presentation of the light. Together, the unconditioned orienting response and the conditioned food-cup response provide quantifiable measures of a cue-related behavior similar to that used to assess cue detection by Parikh et al. (2007). 
As shown in Figure $11 A$, M1 knockout mice exhibited less unconditioned orienting during initial presentations of the light stimulus than did wild-type mice. This was confirmed by a rANOVA, which revealed a significant main effect of Group $\left[F_{(1,16)}=6.8 ; p<0.02\right]$. Importantly, there was no group difference in the amount of orienting observed during the $5 \mathrm{~s}$ period before the onset of the light $\left[F_{(1,16)}=1.9, p>0.2\right]$. Indeed, both groups exhibited very little spontaneous orienting during the prestimulus period $(7.6 \pm 1.2$ and $9.6 \pm 1.9 \%$ for M1 knockout and wild-type mice, respectively). Likewise, there was no group difference in locomotor activity when mice were allowed to explore the open-field apparatus (mean distances traveled were $2.2 \pm 0.1$ and $2.1 \pm 0.2 \mathrm{~m}$ for wild-type and M1 knock-out animals, respectively), and no significant correlation between orienting behavior and locomotor activity. During the conditioning sessions (Fig. $11 \mathrm{~B}$ ), conditioned food-cup behavior during the stimulus was consistently reduced in M1lacking mice, with a significant main effect of Group $\left[F_{(1,16)}=9.8, p<0.01\right]$. Although M1-lacking mice were found to have deficits in conditioned food-cup behavior, they performed better during later trials, indicating that $\mathrm{M} 1$ receptors facilitate, but are not absolutely necessary for, the establishment of cue-reward associations. Because cholinergic input to the mPFC occurs during cue detection (Parikh et al., 2007), our data suggest that cortical M1 receptors may contribute to behavior by modulating the output of pyramidal neurons in the prefrontal cortex.

\section{Discussion}

Our results demonstrate that M1 receptors play a central role in cholinergic modulation of pyramidal neuron excitability. M1 receptors are both necessary and sufficient for phasic cholinergic signaling, including the generation of transient inhibitory responses from the RMP in layer 5 neurons, and inhibition followed by spike acceleration in pyramidal neurons in layers 5 and 2/3. M1 receptors are also necessary for tonic cholinergic signaling but sufficient only for carbachol-induced depolarization of the RMP and for the appearance of robust ADPs. Tonic cholinergic suppression of the AHP requires the additional presence of $\mathrm{M} 3$ receptors. Our results demonstrate that $\mathrm{M} 1$ receptors are coupled to diverse signaling mechanisms capable of generating both excitatory and inhibitory responses in the same target neurons. Furthermore, we provide evi-
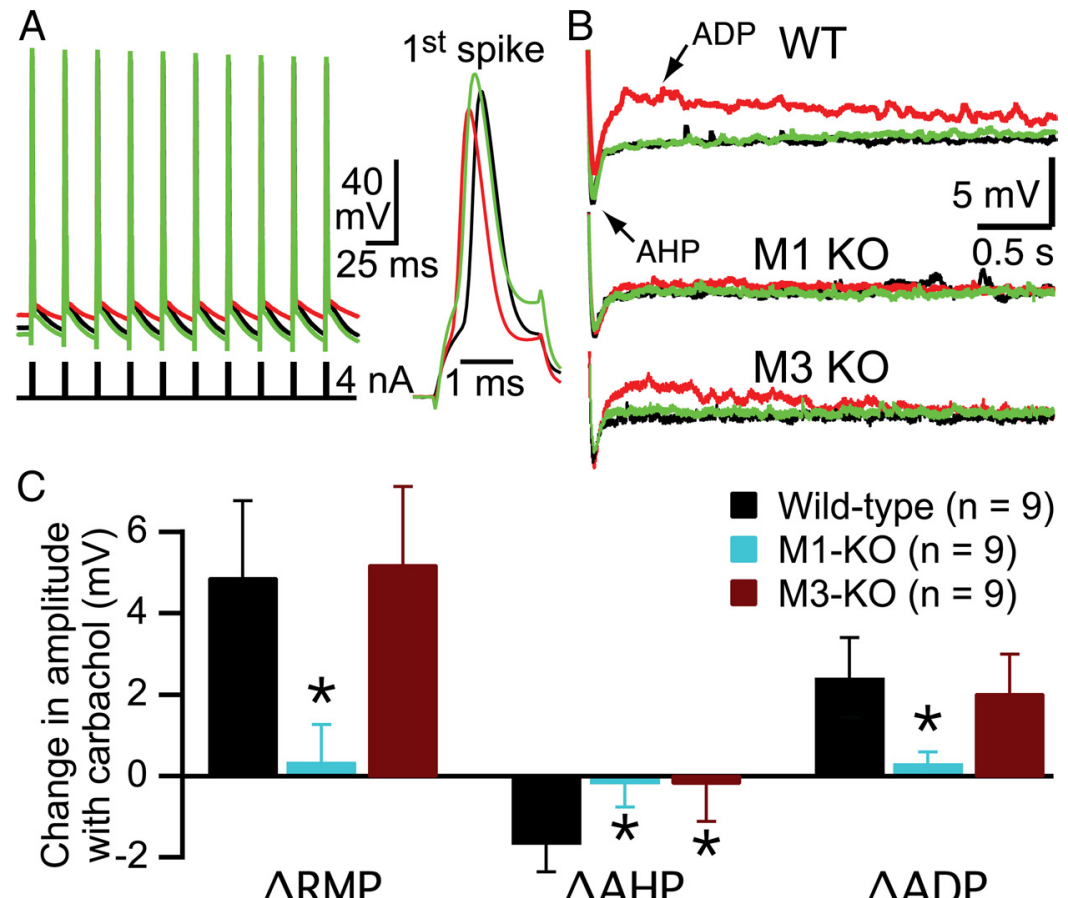

Wild-type $(\mathrm{n}=9)$

M1-KO $(n=9)$

$\mathrm{M} 3-\mathrm{KO}(\mathrm{n}=9)$
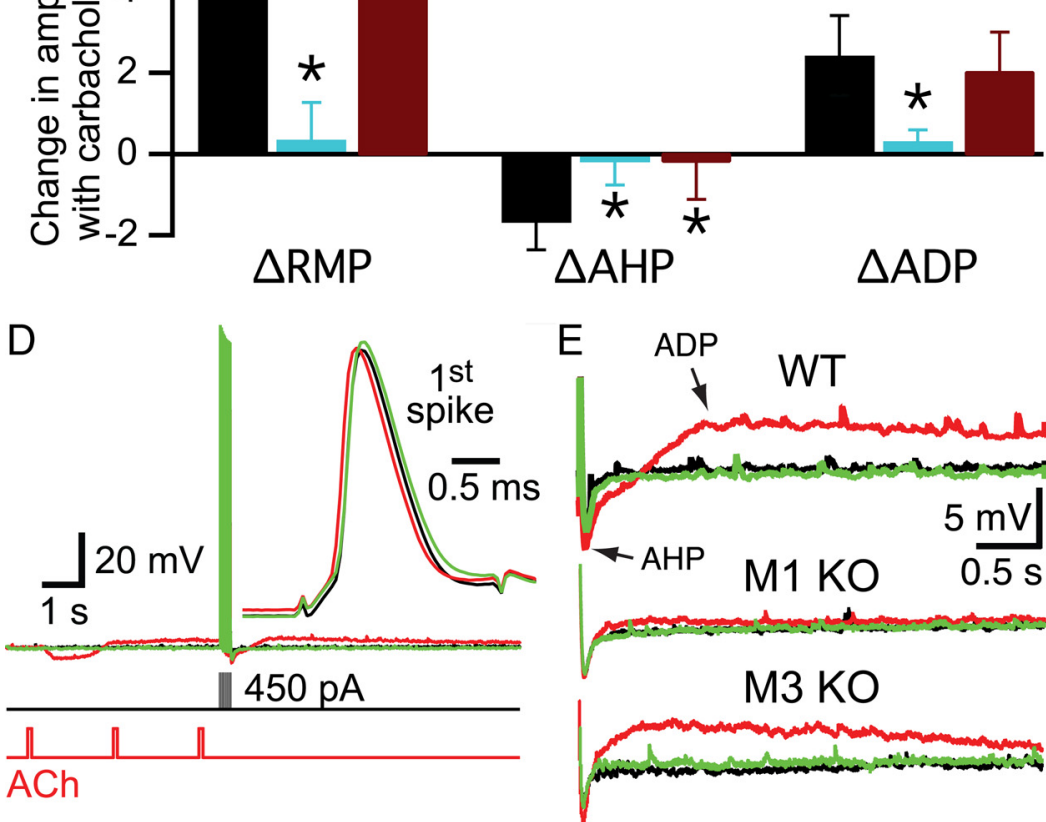

$\mathrm{F}$

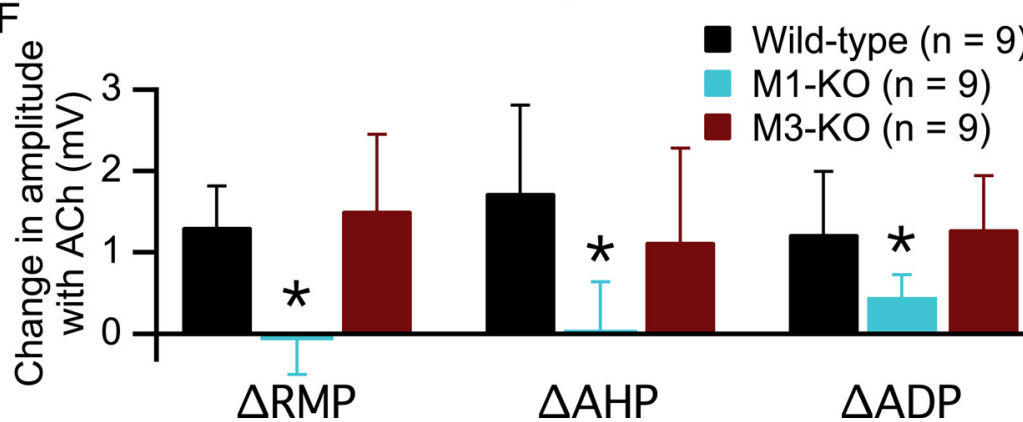

Figure 10. M1 and M3 receptors mediate tonic cholinergic effects on the AHP even in the absence of changes in spike number. A, Superimposed spike trains of 10 action potentials in baseline conditions (black) after 5 min of exposure to carbachol (10 $\mu \mathrm{m}$; red) and after 10 min of wash (green). Single spikes were generated by brief ( $2 \mathrm{~ms})$, high-amplitude ( $4 \mathrm{nA}$ ) current injections delivered at $40 \mathrm{~Hz}$. Notice that bath-applied carbachol reversibly depolarized this neuron. At right, the first spike of each train is expanded after subtracting differences in resting potential. Differences in spike shape the result from slow changes in series resistance over the course of the experiment. $\boldsymbol{B}$, Traces showing AHPs and ADPs following the spikes generated in $\boldsymbol{A}$ (wild-type neuron; top) and following similar trains generated in neurons lacking either M1 (middle) or M3 (bottom) receptors. C, Summary of effects of bath-applied carbachol on RMPs, AHPs, and ADPs of neurons from wild-type, M1 knock-out, and M3 knock-out animals. D, Tonic-like cholinergic effects generated by three brief (100 ms) applications of ACh before a train of 10 action potentials in a wild-type neuron. The first spike of each train is enlarged and inset at right. $\boldsymbol{E}$, AHPs and ADPs in wild-type (top), M1-lacking (middle), and M3-lacking (bottom) neurons following 10 action potentials (delivered at $40 \mathrm{~Hz}$ ) generated before (black), immediately after (red), or 20 s following (green) three focal ACh applications. F, Summary of effects of focal ACh on RMPs, AHPs, and ADPs in wild-type, M1-lacking, and M3-lacking neurons. K0, Knock-out; WT, wild type. 

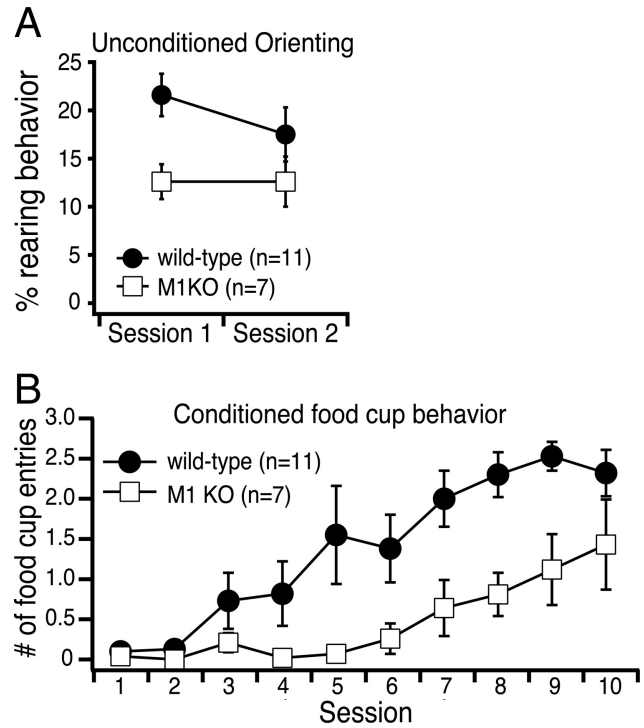

Figure 11. M1 receptors facilitate cue detection. $A$, Orienting behavior in response to an unconditioned light stimulus measured in wild-type and M1-lacking mice on two sequential days preceding the conditioning phase of the experiment. M1 knock-out mice showed significantly less rearing behavior to the stimulus $(p<0.02)$. $\boldsymbol{B}$, Acquisition of the conditioned cue detection behavior, as measured by food-cup entries, is impaired in M1 knock-out animals ( $p<0.01)$. K0, Knock-out.

dence that M1 receptors contribute to cue detection behaviors in mice.

\section{Muscarinic receptors in the neocortex}

In accordance with their prominent role in regulating cortical excitability, $m 1$ RNA transcripts and M1 proteins are more abundant in the cerebral cortex (comprising 50\% of total mAChR expression) than are RNA transcripts and proteins for other mAChR subtypes (Levey et al., 1991, 1993; Wei et al., 1994; Flynn et al., 1995; Krejci and Tucek, 2002; Tayebati et al., 2006). Indeed, M1 receptors are the major $\mathrm{mAChR}$ involved in cortical $\mathrm{G}_{\mathrm{q}}-$ mediated phosphoinositide turnover (Porter et al., 2002; Bymaster et al., 2003). Consistent with their role in normal cognition, M1 expression in the cortex is reduced in both Alzheimer's disease (Flynn et al., 1995; Shiozaki et al., 2001) and normal aging (Tayebati et al., 2006) and reductions in M1 receptor density are correlated with decreased cognitive performance (Tayebati et al., 2006; Hu et al., 2009). Our findings suggest that dysregulation of pyramidal neuron excitability may contribute to M1-linked cognitive deficits.

M3 receptors are the second most common M1-like mAChR in the cortex, comprising $\sim 10 \%$ of total mAChR expression (Levey et al., 1994; Flynn et al., 1995; Tayebati et al., 2006). However, little is known about M3 receptor function in the cortex (but see Semba and White, 1997). Our results demonstrate a role for M3 receptors in regulating the output of cortical pyramidal neurons via modulation of the conductances underlying the AHP. AHP suppression was also dependent on M1 receptor expression, suggesting that M1 and M3 receptors may form heterodimers (Goin and Nathanson, 2006) or otherwise colocalize in cortical pyramidal neurons, perhaps in the proximal apical dendrite in which conductances underlying the AHP have been suggested to reside (Sah and Bekkers, 1996). Although the subcellular distribution of M3 receptors is not yet established, M1 receptors have been identified in proximal apical dendrites (Mrzljak et al., 1993; Shiozaki et al., 2001).
The third M1-like mAChR subtype, the M5 receptor, is expressed at very low levels within the neocortex ( $~ 5 \%$ of total mAChR expression; Flynn et al., 1995; Tayebati et al., 2006), in which they appear to be involved primarily in regulating cerebral blood flow via dilation of vascular tissue (Elhusseiny et al., 1999; Araya et al., 2006). Our experiments failed to demonstrate a direct role for M5 receptors in modulating pyramidal neuron excitability. Additional work will be required to test whether M5 receptors mediate cholinergic signaling in other types of cortical neurons.

Finally, the neocortex expresses both "M2-like" mAChRs (M2 and M4 receptors), with each subtype accounting for 15-20\% of total mAChR expression (Flynn et al., 1995). However, the dependency of cholinergic effects on $\mathrm{G}_{\mathrm{q}}$-related signal transduction (Gulledge and Stuart, 2005), as well as the absence of cholinergic effects in M1-lacking pyramidal neurons, suggests M2 and M4 receptors may not modulate pyramidal neuron excitability directly. Instead, "M2-like" mAChRs are expressed in axon terminals in which they regulate transmitter release from glutamatergic (Vidal and Changeux, 1993; Kimura and Baughman, 1997; Carr and Surmeier, 2007) and GABAergic (Kruglikov and Rudy, 2008) neurons (but see Mrzljak et al., 1998). Therefore, in the in vivo cortical network, M2 and/or M4 receptors (together with other mAChRs; see, for instance, Kremin et al., 2006) likely influence pyramidal neuron activity indirectly by modulating synaptic integration.

\section{M1 receptor signaling in cortical pyramidal neurons}

How does a single receptor subtype, the M1 receptor, mediate opposing physiological responses in the same target neuron? As with other M1-like mAChRs, M1 receptors are coupled to $\mathrm{G}_{\mathrm{q}} \alpha$ subunits that are in turn coupled to the activation of phospholipase C (PLC). PLC cleavage of phosphatidylinositol 4,5bisphosphate $\left(\mathrm{PIP}_{2}\right)$ generates two biologically active second messengers, diacylglycerol (DAG) and $\mathrm{IP}_{3}$. Although $\mathrm{IP}_{3}$-induced calcium release from intracellular stores mediates cholinergic inhibitory responses (Gulledge and Stuart, 2005), it is possible that DAG or PLC-induced reductions of $\mathrm{PIP}_{2}$ in the plasma membrane are involved in generating cholinergic excitation. DAG (Hofmann et al., 1999) and $\mathrm{PIP}_{2}$ reduction (Young et al., 2005; Otsuguro et al., 2008) can each independently activate cationic conductances similar to those thought to mediate cholinergic excitation (Schwindt et al., 1988; Andrade, 1991; Haj-Dahmane and Andrade, 1996, 1998; Egorov et al., 2003), and M1-receptormediated $\mathrm{PIP}_{2}$-depletion may also contribute to cholinergic depolarization by suppressing potassium conductances (Zhang et al., 2003; Carr and Surmeier, 2007). Alternative mechanisms by which M1 receptors might generate excitatory responses independent of PLC signaling include activation of Src kinase (Rosenblum et al., 2000), an enzyme implicated in cholinergic modulation of synaptic plasticity in the hippocampus (Scheiderer et al., 2008). Src kinase can phosphorylate other signaling molecules, including soluble guanylyl cyclase (Murthy, 2008), which has been implicated in cholinergic excitation of hippocampal neurons (Kuzmiski and MacVicar, 2001). Additional studies will be needed to clarify the specific molecular and ionic events linking M1 receptors to the excitatory effects of ACh.

\section{Cell type specificity in cholinergic signaling}

Layer 5 pyramidal neurons were modulated by ACh and carbachol to a greater degree than were neurons in layer $2 / 3$. This finding in the mouse is in agreement with our previous data in the rat (Gulledge et al., 2007) and suggests that layer specificity in 
cholinergic signaling may be a generalized feature of the neocortex. Cell-type specificity of cholinergic signaling also occurs in the hippocampus, in which ACh preferentially inhibits CA1 neurons rather than CA3 cells (Gulledge and Kawaguchi, 2007). Thus, ACh appears to inhibit projection (layer 5 and CA1), rather than intrinsically connected (layer $2 / 3$ and CA3), pyramidal neurons. Why might superficial pyramidal neurons be less responsive to ACh? Cholinergic afferents are present in all cortical layers (Houser et al., 1985; Stewart et al., 1985; Kitt et al., 1994), and cholinergic stimulation of superficial pyramidal neurons enhances calcium release in proximal dendrites following brief spike trains (Cho et al., 2008). Therefore, differences in cholinergic responsiveness may reflect differential expression of SK channels. Indeed, SK channels are expressed at higher levels in layer 5 than in layer 2/3 (Stocker and Pedarzani, 2000; Sailer et al., 2002). Alternatively, preferential expression of the calciumbinding protein calbindin by superficial pyramidal neurons (Kawaguchi, 2003) might interfere with the calcium signaling required for ACh-initiated SK channel activation.

\section{Functional significance}

Recent in vivo data have revealed that transient increases in $\mathrm{ACh}$, lasting only a few seconds, occur in the mPFC of rats performing cue detection tasks (Parikh et al., 2007). Remarkably, these phasic increases in cortical ACh are predictive of successful behavioral performance. Our behavioral data confirm that M1 receptors facilitate cue detection behaviors in mice, whereas our in vitro data suggest that transient increases in ACh during successful cue detection will preferentially inhibit the output of layer 5 pyramidal neurons before facilitating action potential generation in pyramidal neurons in both layers $2 / 3$ and 5 .

Why do layer 5 pyramidal neurons exhibit two opposing cholinergic responses? Transient cholinergic inhibition may act to "reset" populations of layer 5 neurons by hyperpolarizing them to a common membrane potential to allow subsequent synaptic integration to proceed from a uniform level of cellular excitability. In our experiments, neurons were excited via constant current injection (see, for instance, Fig. 1). Neurons in vivo are not expected to experience such monotonic excitatory drive, and therefore, their ability to recover from SK-channel-mediated hyperpolarization will depend on the state of ongoing network activity. Cholinergic hyperpolarization of layer 5 neurons might reduce local reciprocal excitatory drive and therefore limit action potential output to a subset of neurons receiving sufficient excitatory input from superficial layers to overcome the SK-mediated inhibition. Presynaptic effects of ACh on glutamate (Hasselmo and Bower, 1992; Vidal and Changeux, 1993; Kimura and Baughman, 1997) and GABA (Kruglikov and Rudy, 2008) release, as well as direct cholinergic modulation of cortical interneurons (Kawaguchi, 1997; Porter et al., 1999; Christophe et al., 2002; Gulledge et al., 2007), will further sculpt network activity by enhancing glutamate release from afferent excitatory terminals while suppressing glutamatergic transmission at intracortical synapses (Hasselmo and Bower, 1992) and by preferentially exciting nicotinic receptor-expressing interneurons (Porter et al., 1999; Christophe et al., 2002; Gulledge et al., 2007) while decreasing GABAergic inhibition of pyramidal neurons via inhibition of large CCK-expressing basket neurons (Kawaguchi, 1997; Gulledge et al., 2007) and suppression of GABA release from fast-spiking interneurons (Kruglikov and Rudy, 2008).

In a previous cue detection task, transient $\mathrm{ACh}$ release into the $\mathrm{mPFC}$ is temporally correlated not with cue presentation but rather with the timing of expected reward delivery (Parikh et al.,
2007). This suggests that prefrontal ACh release is more important for decision-making (i.e., selection of behavior) than for recognition of cue salience. Our data suggest cholinergic inhibition may assist this decision-making process by increasing the signal-to-noise of cortical processing not only by limiting action potential output to neurons receiving the most convergent excitatory drive but also by transiently amplifying that output until cortical ACh levels subside.

\section{References}

Andrade R (1991) Cell excitation enhances muscarinic cholinergic responses in rat association cortex. Brain Res 548:81-93.

Araya R, Noguchi T, Yuhki M, Kitamura N, Higuchi M, Saido TC, Seki K, Itohara S, Kawano M, Tanemura K, Takashima A, Yamada K, Kondoh Y, Kanno I, Wess J, Yamada M (2006) Loss of M5 muscarinic acetylcholine receptors leads to cerebrovascular and neuronal abnormalities and cognitive deficits in mice. Neurobiol Dis 24:334-344.

Barkai E, Hasselmo ME (1994) Modulation of the input/output function of rat piriform cortex pyramidal cells. J Neurophysiol 72:644-658.

Bymaster FP, Carter PA, Yamada M, Gomeza J, Wess J, Hamilton SE, Nathanson NM, McKinzie DL, Felder CC (2003) Role of specific muscarinic receptor subtypes in cholinergic parasympathomimetic responses, in vivo phosphoinositide hydrolysis, and pilocarpine-induced seizure activity. Eur J Neurosci 17:1403-1410.

Carr DB, Surmeier DJ (2007) M1 muscarinic receptor modulation of Kir2 channels enhances temporal summation of excitatory synaptic potentials in prefrontal cortex pyramidal neurons. J Neurophysiol 97:3432-3438.

Chess AC, Bucci DJ (2006) Increased concentration of cerebral kynurenic acid alters stimulus processing and conditioned responding. Behav Brain Res 170:326-332.

Cho KH, Jang HJ, Lee EH, Yoon SH, Hahn SJ, Jo YH, Kim MS, Rhie DJ (2008) Differential cholinergic modulation of $\mathrm{Ca}^{2+}$ transients evoked by backpropagating action potentials in apical and basal dendrites of cortical pyramidal neurons. J Neurophysiol 99:2833-2843.

Christophe E, Roebuck A, Staiger JF, Lavery DJ, Charpak S, Audinat E (2002) Two types of nicotinic receptors mediate an excitation of neocortical layer I interneurons. J Neurophysiol 88:1318-1327.

Clader JW, Wang Y (2005) Muscarinic receptor agonists and antagonists in the treatment of Alzheimer's disease. Curr Pharm Des 11:3353-3361.

Eglen RM, Choppin A, Dillon MP, Hegde S (1999) Muscarinic receptor ligands and their therapeutic potential. Curr Opin Chem Biol 3:426-432.

Egorov AV, Hamam BN, Fransén E, Hasselmo ME, Alonso AA (2002) Graded persistent activity in entorhinal cortex neurons. Nature 420:173-178.

Egorov AV, Angelova PR, Heinemann U, Müller W (2003) $\mathrm{Ca}^{2+}$ independent muscarinic excitation of rat medial entorhinal cortex layer $\mathrm{V}$ neurons. Eur J Neurosci 18:3343-3351.

Elhusseiny A, Cohen Z, Olivier A, Stanimirović DB, Hamel E (1999) Functional acetylcholine muscarinic receptor subtypes in human brain microcirculation: identification and cellular localization. J Cereb Blood Flow Metab 19:794-802.

Fisher A (2008) M1 muscarinic agonists target major hallmarks of Alzheimer's disease - the pivotal role of brain M1 receptors. Neurodegener Dis 5:237-240.

Flynn DD, Ferrari-DiLeo G, Mash DC, Levey AI (1995) Differential regulation of molecular subtypes of muscarinic receptors in Alzheimer's disease. J Neurochem 64:1888-1891.

Gallagher M, Graham PW, Holland PC (1990) The amygdala central nucleus and appetitive Pavlovian conditioning: lesions impair one class of conditioned behavior. J Neurosci 10:1906-1911.

Goin JC, Nathanson NM (2006) Quantitative analysis of muscarinic acetylcholine receptor homo- and heterodimerization in live cells: regulation of receptor down-regulation by heterodimerization. J Biol Chem 281:5416-5425.

Gulledge AT, Kawaguchi Y (2007) Phasic cholinergic signaling in the hippocampus: functional homology with the neocortex? Hippocampus $17: 327-332$.

Gulledge AT, Stuart GJ (2005) Cholinergic inhibition of neocortical pyramidal neurons. J Neurosci 25:10308-10320.

Gulledge AT, Park SB, Kawaguchi Y, Stuart GJ (2007) Heterogeneity of pha- 
sic cholinergic signalling in neocortical neurons. J Neurophysiol 97:2215-2229.

Haj-Dahmane S, Andrade R (1996) Muscarinic activation of a voltagedependent cation nonselective current in rat association cortex. J Neurosci 16:3848-3861.

Haj-Dahmane S, Andrade R (1998) Ionic mechanism of the slow afterdepolarization induced by muscarinic receptor activation in rat prefrontal cortex. J Neurophysiol 80:1197-1210.

Halliwell JV (1989) Cholinergic responses in human neocortical neurones. EXS 57:138-149.

Hasselmo ME, Bower JM (1992) Cholinergic suppression specific to intrinsic not afferent fiber synapses in rat piriform (olfactory) cortex. J Neurophysiol 67:1222-1229.

Hofmann T, Obukhov AG, Schaefer M, Harteneck C, Gudermann T, Schultz G (1999) Direct activation of human TRPC6 and TRPC3 channels by diacylglycerol. Nature 397:259-263.

Holland PC (1977) Conditioned stimulus as a determinant of the form of the Pavlovian conditioned response. J Exp Psychol Anim Behav Process 3:77-104.

Holland PC (1984) Origins of behavior in Pavlovian conditioning. In: The psychology of learning and motivation, pp 129-174. New York: Academic Press.

Houser CR, Crawford GD, Salvaterra PM, Vaughn JE (1985) Immunocytochemical localization of choline acetyltransferase in rat cerebral cortex: a study of cholinergic neurons and synapses. J Comp Neurol 234:17-34.

Hu Y, Wang Z, Zhang R, Wu P, Xia Z, Orsi A, Rees D (2009) Regulation of $\mathrm{M}(1)$-receptor mRNA stability by smilagenin and its significance in improving memory of aged rats. Neurobiol Aging. Advance online publication. Retrieved July 23, 2008. doi:10.1016/jneurobiolaging.2008.06.008.

Kawaguchi Y (1997) Selective cholinergic modulation of cortical GABAergic cell subtypes. J Neurophysiol 78:1743-1747.

Kawaguchi Y (2003) Local circuit neurons in the frontal cortico-striatal system. In: Excitatory-inhibitory balance: synapses, circuits, systems (Hensch TK, Fagiolini M eds), pp 125-148. London: Kluwer Academic/Plenum Publishers.

Kaye H, Pearce JM (1984) The strength of the orienting response during Pavlovian conditioning. J Exp Psychol Anim Behav Process 10:90-109.

Kimura F, Baughman RW (1997) Distinct muscarinic receptor subtypes suppress excitatory and inhibitory synaptic responses in cortical neurons. J Neurophysiol 77:709-716.

Kitt CA, Höhmann C, Coyle JT, Price DL (1994) Cholinergic innervation of mouse forebrain structures. J Comp Neurol 341:117-129.

Klink R, Alonso A (1997) Ionic mechanisms of muscarinic depolarization in entorhinal cortex layer II neurons. J Neurophysiol 77:1829-1843.

Krejcí A, Tucek S (2002) Quantitation of mRNAs for M(1) to M(5) subtypes of muscarinic receptors in rat heart and brain cortex. Mol Pharmacol 61:1267-1272.

Kremin T, Gerber D, Giocomo LM, Huang SY, Tonegawa S, Hasselmo ME (2006) Muscarinic suppression in stratum radiatum of CA1 shows dependence on presynaptic $\mathrm{M} 1$ receptors and is not dependent on effects at GABA(B) receptors. Neurobiol Learn Mem 85:153-163.

Kruglikov I, Rudy B (2008) Perisomatic GABA release and thalamocortical integration onto neocortical excitatory cells are regulated by neuromodulators. Neuron 58:911-924.

Kuzmiski JB, MacVicar BA (2001) Cyclic nucleotide-gated channels contribute to the cholinergic plateau potential in hippocampal CA1 pyramidal neurons. J Neurosci 21:8707-8714.

Lang PJ, Simons RF, Balaban M (1997) Attention and orienting: sensory and motivational processes. Mahwah, NJ: Lawrence Eribaum and Associates.

Lanzafame AA, Christopoulos A, Mitchelson F (2003) Cellular signaling mechanisms for muscarinic acetylcholine receptors. Receptors Channels 9:241-260.

Levey AI (1993) Immunological localization of m1-m5 muscarinic acetylcholine receptors in peripheral tissues and brain. Life Sci 52:441-448.

Levey AI, Kitt CA, Simonds WF, Price DL, Brann MR (1991) Identification and localization of muscarinic acetylcholine receptor proteins in brain with subtype-specific antibodies. J Neurosci 11:3218-3226.

Levey AI, Edmunds SM, Heilman CJ, Desmond TJ, Frey KA (1994) Localization of muscarinic $\mathrm{m} 3$ receptor protein and $\mathrm{M} 3$ receptor binding in rat brain. Neuroscience 63:207-221.

Matsui M, Motomura D, Karasawa H, Fujikawa T, Jiang J, Komiya Y, Takahashi
S, Taketo MM (2000) Multiple functional defects in peripheral autonomic organs in mice lacking muscarinic acetylcholine receptor gene for the M3 subtype. Proc Natl Acad Sci U S A 97:9579-9584.

McCormick DA, Prince DA (1986) Acetylcholine induces burst firing in thalamic reticular neurones by activating a potassium conductance. Nature 319:402-405.

Mrzljak L, Levey AI, Goldman-Rakic PS (1993) Association of m1 and m2 muscarinic receptor proteins with asymmetric synapses in the primate cerebral cortex: morphological evidence for cholinergic modulation of excitatory neurotransmission. Proc Natl Acad Sci U S A 90:5194-5198.

Mrzljak L, Levey AI, Belcher S, Goldman-Rakic PS (1998) Localization of the $\mathrm{m} 2$ muscarinic acetylcholine receptor protein and mRNA in cortical neurons of the normal and cholinergically deafferented rhesus monkey. J Comp Neurol 390:112-132.

Murthy KS (2008) Inhibitory phosphorylation of soluble guanylyl cyclase by muscarinic $\mathrm{m} 2$ receptors via $\mathrm{G} \beta \gamma$-dependent activation of c-Src kinase. J Pharmacol Exp Ther 325:183-189.

Nakamura T, Matsui M, Uchida K, Futatsugi A, Kusakawa S, Matsumoto N, Nakamura K, Manabe T, Taketo MM, Mikoshiba K (2004) M(3) muscarinic acetylcholine receptor plays a critical role in parasympathetic control of salivation in mice. J Physiol 558:561-575.

Ohno-Shosaku T, Matsui M, Fukudome Y, Shosaku J, Tsubokawa H, Taketo MM, Manabe T, Kano M (2003) Postsynaptic M1 and M3 receptors are responsible for the muscarinic enhancement of retrograde endocannabinoid signalling in the hippocampus. Eur J Neurosci 18:109-116.

Otsuguro K, Tang J, Tang Y, Xiao R, Freichel M, Tsvilovskyy V, Ito S, Flockerzi V, Zhu MX, Zholos AV (2008) Isoform-specific inhibition of TRPC4 channel by phosphatidylinositol 4,5-bisphosphate. J Biol Chem 283:10026-10036.

Parikh V, Kozak R, Martinez V, Sarter M (2007) Prefrontal acetylcholine release controls cue detection on multiple timescales. Neuron 56:141-154.

Porter AC, Bymaster FP, DeLapp NW, Yamada M, Wess J, Hamilton SE, Nathanson NM, Felder CC (2002) M1 muscarinic receptor signaling in mouse hippocampus and cortex. Brain Res 944:82-89.

Porter JT, Cauli B, Tsuzuki K, Lambolez B, Rossier J, Audinat E (1999) Selective excitation of subtypes of neocortical interneurons by nicotinic receptors. J Neurosci 19:5228-5235.

Ringman JM, Cummings JL (2006) Current and emerging pharmacological treatment options for dementia. Behav Neurol 17:5-16.

Rosenblum K, Futter M, Jones M, Hulme EC, Bliss TV (2000) ERKI/II regulation by the muscarinic acetylcholine receptors in neurons. J Neurosci 20:977-985.

Sah P, Bekkers JM (1996) Apical dendritic location of slow afterhyperpolarization current in hippocampal pyramidal neurons: implications for the integration of long-term potentiation. J Neurosci 16:4537-4542.

Sailer CA, Hu H, Kaufmann WA, Trieb M, Schwarzer C, Storm JF, Knaus HG (2002) Regional differences in distribution and functional expression of small-conductance $\mathrm{Ca}^{2+}$-activated $\mathrm{K}^{+}$channels in rat brain. J Neurosci 22:9698-9707.

Scheiderer CL, Smith CC, McCutchen E, McCoy PA, Thacker EE, Kolasa K, Dobrunz LE, McMahon LL (2008) Coactivation of M(1) muscarinic and $\alpha 1$ adrenergic receptors stimulates extracellular signal-regulated protein kinase and induces long-term depression at CA3-CA1 synapses in rat hippocampus. J Neurosci 28:5350-5358.

Schwindt PC, Spain WJ, Foehring RC, Chubb MC, Crill WE (1988) Slow conductances in neurons from cat sensorimotor cortex in vitro and their role in slow excitability changes. J Neurophysiol 59:450-467.

Semba K, White TD (1997) M3 muscarinic receptor-mediated enhancement of NMDA-evoked adenosine release in rat cortical slices in vitro. J Neurochem 69:1066-1072.

Shiozaki K, Iseki E, Hino H, Kosaka K (2001) Distribution of m1 muscarinic acetylcholine receptors in the hippocampus of patients with Alzheimer's disease and dementia with Lewy bodies-an immunohistochemical study. J Neurol Sci 193:23-28.

Stewart DJ, MacFabe DF, Leung LW (1985) Topographical projection of cholinergic neurons in the basal forebrain to the cingulate cortex in the rat. Brain Res 358:404-407.

Stocker M, Pedarzani P (2000) Differential distribution of three $\mathrm{Ca}^{2+}$. activated $\mathrm{K}^{+}$channel subunits, SK1, SK2, and SK3, in the adult rat central nervous system. Mol Cell Neurosci 15:476-493.

Tang AC, Bartels AM, Sejnowski TJ (1997) Effects of cholinergic modula- 
tion on responses of neocortical neurons to fluctuating input. Cereb Cortex 7:502-509.

Tayebati SK, Di Tullio MA, Amenta F (2006) Muscarinic cholinergic receptor subtypes in cerebral cortex of Fisher 344 rats: a light microscope autoradiography study of age-related changes. Mech Ageing Dev 127: $115-122$.

Vidal C, Changeux JP (1993) Nicotinic and muscarinic modulations of excitatory synaptic transmission in the rat prefrontal cortex in vitro. Neuroscience 56:23-32.

Wei J, Walton EA, Milici A, Buccafusco JJ (1994) m1-m5 muscarinic receptor distribution in rat CNS by RT-PCR and HPLC. J Neurochem 63:815-821.
Williams SH, Constanti A (1988) Quantitative effects of some muscarinic agonists on evoked surface-negative field potentials recorded from the guinea-pig olfactory cortex slice. Br J Pharmacol 93:846-854.

Young KW, Billups D, Nelson CP, Johnston N, Willets JM, Schell MJ, Challiss RA, Nahorski SR (2005) Muscarinic acetylcholine receptor activation enhances hippocampal neuron excitability and potentiates synaptically evoked $\mathrm{Ca}^{2+}$ signals via phosphatidylinositol 4,5-bisphosphate depletion. Mol Cell Neurosci 30:48-57.

Zhang H, Craciun LC, Mirshahi T, Rohács T, Lopes CM, Jin T, Logothetis DE (2003) PIP(2) activates KCNQ channels, and its hydrolysis underlies receptor-mediated inhibition of M currents. Neuron 37:963975. 